University of Wollongong

Research Online

Faculty of Engineering and Information

Faculty of Engineering and Information

Sciences - Papers: Part A

Sciences

$1-1-2013$

Winkler model for dynamic response of composite caisson-piles

foundations: Lateral response

Rui Zhong

University of Wollongong, rzhong@uow.edu.au

Maosong Huang

Tongji University

Follow this and additional works at: https://ro.uow.edu.au/eispapers

Part of the Engineering Commons, and the Science and Technology Studies Commons

Research Online is the open access institutional repository for the University of Wollongong. For further information contact the UOW Library: research-pubs@uow.edu.au 


\title{
Winkler model for dynamic response of composite caisson-piles foundations: Lateral response
}

\author{
Abstract \\ As the first part of a sequence focusing on the dynamic response of composite caisson-piles foundations \\ (CCPFs1), this paper develops a simplified method for the lateral response of these foundations. A \\ Winkler model for the lateral vibration of the CCPF is created by joining the two components, the caisson \\ and the pile group, where the four-spring Winkler model is utilized for the caisson and axial-lateral coupled \\ vibration equations are derived for the pile group. For determining the coefficients of the four-spring \\ Winkler model for the caissons, embedded footing impedance is used and a modification on the \\ rotational embedment factor is made for the sake of the geometrical difference between shallow footings \\ and caissons. Comparisons against results from finite element simulations demonstrate the reliability of \\ this modified four-spring Winkler model for caissons in both homogenous and layered soils. The \\ proposed simplified method for the lateral vibration of CCPFs is verified also by 3D finite element \\ modeling. Finally, through an example, the idea of adding piles beneath the caisson is proved to be of \\ great significance to enhance the resistance of the foundation against lateral dynamic loads.
}

\section{Keywords}

piles, foundations, lateral, dynamic, response, winkler, composite, model, caisson

Disciplines

Engineering | Science and Technology Studies

\section{Publication Details}

Zhong, R. \& Huang, M. (2013). Winkler model for dynamic response of composite caisson-piles foundations: Lateral response. Soil Dynamics and Earthquake Engineering, 55 182-194. 


\title{
Winkler model for dynamic response of composite caisson-piles foundations: Lateral response
}

\author{
Rui Zhong a, b, Maosong Huang ${ }^{\text {a, b, * }}$ \\ ${ }^{a}$ Department of Geotechnical Engineering, Tongji University, Shanghai 200092, China \\ ${ }^{\mathrm{b}}$ Key Laboratory of Geotechnical and Underground Engineering of Ministry of Education, Tongji \\ University, Shanghai 200092, China
}

*Corresponding author. Tel.: +8602165983980; fax: +8602165983980

E-mail address: mshuang@tongji.edu.cn (M. HUANG)

\begin{abstract}
:
As the first part of a sequence focusing on the dynamic response of composite caisson-piles foundations $\left(\mathrm{CCPFs}^{1}\right)$, this paper develops a simplified method for the lateral response of these foundations. A Winkler model for the lateral vibration of the $\mathrm{CCPF}$ is created by joining the two components, the caisson and the pile group, where the four-spring Winkler model is utilized for the caisson and axial-lateral coupled vibration equations are derived for the pile group. For determining the coefficients of the four-spring Winkler model for the caissons, embedded footing impedance is used and a modification on the rotational embedment factor is made for the sake of the geometrical difference between shallow footings and caissons. Comparisons against results from finite element simulations demonstrate the reliability of this modified four-spring Winkler model for caissons in both homogenous and layered soils. The proposed simplified method for the lateral vibration of CCPFs is verified also by $3 \mathrm{D}$ finite element modeling. Finally, through an example, the idea of adding piles beneath the caisson is proved to be of great significance to enhance the resistance of the foundation against lateral dynamic loads.
\end{abstract}

Key words: composite caisson-piles foundation; lateral response; Winkler model; embedment factor; modification; finite element simulations

\section{Introduction}

The composite caisson-piles foundation (CCPF) was proposed in the

${ }^{1}$ CCPF: composite caisson-piles foundation 
pre-construction investigation report for the highway channel across Qiongzhou straits between the mainland and Hainan Island of China, with the expectation that adding piles beneath the caisson can improve its behavior under lateral and seismic loads. As suggested in the report, the CCPF can be constructed by driving piles from the inside of the caisson after it sinks to the designed depth. The general appearance of the CCPF is a combination of a caisson and grouped piles, as shown in Fig. 1.

Caissons are widely used in bridge engineering and offshore engineering, e.g. Jiangyin Yangtze River Highway Bridge in China and San-Francisco-Oakland Bay Bridge in USA, due to their advantages such as the convenience of underwater construction and the good resistance to the ship collision. However, even though the caisson is often categorized as one of the deep foundation types, its embedment depth cannot compare with that of the pile group. For this reason, what worries us is how caissons would behave under strong lateral or seismic loads. Our confidence may be reduced by the fact that many structures on caissons suffered serious damages during the Kobe 1995 earthquake [1]. The resistance of caissons against lateral dynamic loads is crucial during earthquake since the structure inertial could cause tremendous deformation of the foundations. Gerolymos and Gazetas [1] proposed a four-spring Winkler model in which soils are modeled with four types of springs (associated with dashpots) for the dynamic response of rigid caissons, and a method for calibrating the spring coefficients with the impedance of shallow footings was developed [4 8]. In their companion papers [2,3], this model was extended to consider the soil and interface nonlinearities. In order to back-calculate the Winkler spring coefficients in layered soils, Varun et al. [9] and Varun [10] conducted a number of numerical simulations with the finite element method. Considering the structures supported by caissons, Tsigginos et al. [11] studied the seismic response of the foundation-structure system with a dynamic Winkler model for the foundation. Despite the lack of more enough published research fruits about caissons, there are abundant references in terms of shallow embedded foundations which can enlighten the study of caissons, e.g. the research of Gazetas and Tassoulas [4 5], Hatzikonstantinou et al. [6], Fotopoulou et al. [7], Gazetas [8], Beredugo and Novak [12], Kausel and Roësset [13], and Wolf [14].

Since the CCPF is composited by a caisson and grouped piles, the analysis on it is somewhat complex due to a significant difference between the caisson and the grouped piles. Because of the geometry characteristics, it is reasonable to assume the 
caissons as a rigid body. However, piles are totally different, owing to not only their slenderness but also the interaction among the individual piles. The dynamic response of pile groups were well studied in the past decades. Simplified methods were developed by Gazetas and Makris [15], Makris and Gazetas [16] and Mylonakis and Gazetas [17] for the axial, lateral, as well as seismic response of pile groups. For the layered soils, Wu et al. [18] and Huang et al. [19] adopted the transfer matrix method to study the axial and lateral responses of pile groups based on the dynamic Winkler model.

A simplified approach is developed for the lateral vibration of CCPFs in this paper. The dynamic Winkler models for caissons and pile groups are coupled, generating a composite Winkler model for CCPFs. The spring coefficients for the caisson part are determined through the method proposed by Ref. [1] based on the impedance of shallow footings [4 8]. However, considering the difference of depth-width ratio between caissons (i.e. $0.5<d / B<4$ [1]) and shallow footings (i.e. $d / B \leqslant 1$ [4 8]), the feasibility of the expressions for the shallow footing impedance is checked for their application in caissons, and a modification is made to gain more accurate spring coefficients for caissons. This modification is proved to be meaningful by the finite element method. In order to verify the proposed simplified method for the lateral vibration of CCPFs, a series of 3D finite element simulations are developed and good agreements are reached between the numerical method and the proposed simplified method. Finally, with an example calculated by the proposed simplified method, the significance of adding piles in resisting lateral dynamic loads is studied.

\section{Derivations of lateral impedance of CCPFs in Winkler model}

\subsection{Impedance of $C C P F s$}

A dynamic Winkler model could be created by simplifying the soil resistances with a series of springs (associated with dashpots) for the lateral response of CCPFs, as shown in Fig. 2. The lateral equilibrium equation of the CCPF can be expressed as

$$
\mathbf{K}_{\mathbf{c p}}\left\{\begin{array}{c}
u_{b} \\
\theta
\end{array}\right\}=\mathbf{P}_{\mathbf{b}}
$$

where $u_{b}$ and $\theta$ are the horizontal displacement and the rotation angle of the base center of the caisson part, and $\mathbf{P}_{\mathbf{b}}$ is the load vector given by 


$$
\mathbf{P}_{\mathbf{b}}=\left\{\begin{array}{c}
Q_{0} \\
D Q_{0}+M_{0}
\end{array}\right\}
$$

where $D$ is the length of the caisson part, and $Q_{0}$ and $M_{0}$ are the dynamic horizontal force and moment applied on the top of the CCPF respectively, as shown in Fig. 2.

$\mathbf{K}_{\mathbf{c p}}$, the impedance matrix of the CCPF with respect to the base center of its caisson part, is a two dimensional matrix, i.e.

$$
\mathbf{K}_{\mathbf{c p}}=\left[\begin{array}{cc}
\tilde{K}_{H H}^{c p} & \tilde{K}_{H M}^{c p} \\
\tilde{K}_{M H}^{c p} & \tilde{K}_{M M}^{c p}
\end{array}\right]
$$

and the determination on it in Winkler model is the main purpose of this paper.

For convenience of application, the impedance of the CCPF can also be expressed with respect to its top center by coordinate transformation on $\mathbf{K}_{\mathbf{c p}}$, i.e.

$$
\mathbf{S}=\left[\begin{array}{cc}
\tilde{S}_{H H} & \tilde{S}_{H M} \\
\tilde{S}_{M H} & \tilde{S}_{M M}
\end{array}\right]=\left[\begin{array}{cc}
\tilde{K}_{H H}^{c p} & \tilde{K}_{H M}^{c p}-D \tilde{K}_{H H}^{c p} \\
\tilde{K}_{M H}^{c p}-D \tilde{K}_{H H}^{c p} & \tilde{K}_{M M}^{c p}-D\left(\tilde{K}_{H M}^{c p}+\tilde{K}_{M H}^{c p}\right)+D^{2} \tilde{K}_{H H}^{c p}
\end{array}\right]
$$

where $\widetilde{S}_{H H}, \widetilde{S}_{H M}, \widetilde{S}_{M H}$ and $\widetilde{S}_{M M}$ are named as the complex swaying stiffness, cross swaying-rocking stiffness, cross rocking-swaying stiffness and rocking stiffness respectively, and $\tilde{S}_{H M}=\tilde{S}_{M H}$.

Since the CCPF is a composition of a caisson and a pile group, its impedance matrix $\mathbf{K}_{\mathbf{c p}}$ can be obtained by adding the impedance matrixes of the caisson and the pile group together, namely

$$
\mathbf{K}_{\mathrm{cp}}=\mathbf{K}_{\mathrm{c}}+\mathbf{K}_{\mathbf{p}}
$$

where $\mathbf{K}_{\mathbf{p}}$ and $\mathbf{K}_{\mathbf{c}}$ are the impedance matrixes of the pile group and the caisson respectively, which will be determined in Section 2.2 and 2.3 respectively.

\subsection{Determination of impedance matrix of pile group $\boldsymbol{K}_{\boldsymbol{p}}$}

Although the axial and the lateral vibrations of the pile groups have been well studied in the past [15 19], the work is seldom related to the axial-lateral coupled vibration. However, it is essential to couple the axial vibration into lateral vibration in this study, because the piles will deform vertically once the CCPF rotates, with the vertical reaction forces exerted to the caisson, equivalent to a resultant reaction moment, as shown in Fig. 3.

Through Refs. [15] and [18], considering the pile-pile axial interaction, the axial displacement at the head of a pile (e.g. pile $k$ ) in a pile group is given as 


$$
w_{k}=\sum_{j=1}^{N} \alpha_{k j}^{V} f^{V} V_{j}, \quad k=1 \cdots N
$$

where $N$ is the number of the piles, $V_{j}$ is the axial load undertaken by pile $j, f^{V}$ is the axial flexibility of the sole pile, and $\alpha_{k j}^{V}$ is the axial pile-pile interaction factor between pile $j$ and pile $k$.

Through Refs. [16] and [19], considering the pile-pile lateral interaction, the lateral displacements at the head of a pile (e.g. pile $k$ ) in a pile group are given as

$$
\left\{\begin{array}{l}
u_{k} \\
\theta_{k}
\end{array}\right\}=\sum_{j=1}^{N}\left(\boldsymbol{\alpha}_{\mathbf{k j}}^{\mathbf{H}} \mathbf{f}^{\mathbf{H}}\left\{\begin{array}{c}
H_{j} \\
M_{j}
\end{array}\right\}\right)=\sum_{j=1}^{N}\left(\left[\begin{array}{cc}
\alpha_{u, k j}^{H} & \alpha_{u \theta, k j}^{H} \\
\alpha_{\theta u, k j}^{H} & \alpha_{\theta \theta, k j}^{H}
\end{array}\right]\left[\begin{array}{cc}
f_{u H}^{H} & f_{u M}^{H} \\
f_{\theta H}^{H} & f_{\theta M}^{H}
\end{array}\right]\left\{\begin{array}{c}
H_{j} \\
M_{j}
\end{array}\right\}\right)
$$

where $H_{j}$ and $M_{j}$ are the horizontal load and moment undertaken by pile $j, \mathbf{f}^{\mathbf{H}}$ is the lateral flexibility matrix of the sole pile, and $\boldsymbol{\alpha}_{\mathbf{k j}}^{\mathbf{H}}$ is the lateral pile-pile interaction matrix between pile $j$ and pile $k$.

The derivation of Eqs. (6) and (7) is introduced in the appendix.

When both axial and lateral harmonic loads are applied on the cap, the pile group will perform with an axial-lateral coupled vibration, as shown in Fig. 4, where $V^{G}, H^{G}$ and $M^{G}$ represent vertical load, horizontal load and moment applied on the pile group, and $w^{G}, u^{G}$ and $\theta^{G}$ represent vertical displacement, horizontal displacement and rotation angle of the cap respectively. In Fig. 4, the positive directions of the vertical, horizontal and rotational axes are defined as downward, rightward and clockwise respectively.

For pile $k$ beneath the cap, the vertical displacement $w_{k}$, horizontal displacement $u_{k}$ and rotation angle $\theta_{k}$ at its head have a relation with the displacements and rotation angle of the cap, i.e.

$$
\begin{aligned}
w_{k} & =w^{G}+x_{k} \theta^{G} \\
u_{k} & =u^{G}-x_{k}\left(\theta^{G}\right)^{2} \approx u^{G} \\
\theta_{k} & =\theta^{G}
\end{aligned}
$$

where $x_{k}$ is the $x$ coordinate of the location of pile $k$, in a coordinate system that defines the origin of $x$ axis as the center of the cap, and the positive direction as rightward.

The resultant forces of the loads undertaken by all the piles must equal the loads applied on the cap, hence

$$
\sum_{k=1}^{N} V_{k}=V^{G}
$$




$$
\begin{aligned}
& \sum_{k=1}^{N} H_{k}=H^{G} \\
& \sum_{k=1}^{N}\left(M_{k}+V_{k} x_{k}\right)=M^{G}
\end{aligned}
$$

The overall equation for axial-lateral coupled vibration obtained by putting Eqs. (6) $\sim(13)$ together can be expressed as

$$
\left[\begin{array}{cccc}
\mathbf{O} & \mathbf{A}_{12} & \mathbf{A}_{13} & \mathbf{A}_{14} \\
\mathbf{A}_{21} & \mathbf{A}_{22} & \mathbf{A}_{23} & \mathbf{O} \\
\mathbf{A}_{31} & \mathbf{A}_{32} & \mathbf{A}_{33} & \mathbf{O} \\
\mathbf{A}_{41} & \mathbf{O} & \mathbf{O} & \mathbf{A}_{44}
\end{array}\right]\left\{\begin{array}{c}
\mathbf{u}^{\mathbf{G}} \\
\mathbf{H} \\
\mathbf{M} \\
\mathbf{V}
\end{array}\right\}=\left\{\begin{array}{c}
\mathbf{P}^{\mathbf{G}} \\
\mathbf{O} \\
\mathbf{O} \\
\mathbf{O}
\end{array}\right\}
$$

where the vertical degree of freedom of the cap center is removed because it has no effect on the lateral impedance matrix of the pile group. $\mathbf{u}^{\mathbf{G}}$ and $\mathbf{P}^{\mathbf{G}}$ are the displacement and external force vectors, which are

$$
\begin{aligned}
\mathbf{u}^{\mathbf{G}} & =\left\{\begin{array}{c}
u^{G} \\
\theta^{G}
\end{array}\right\} \\
\mathbf{P}^{\mathbf{G}} & =\left\{\begin{array}{l}
H^{G} \\
M^{G}
\end{array}\right\}
\end{aligned}
$$

and $\mathbf{H}, \mathbf{M}, \mathbf{V}$ and $\mathbf{A}_{12} \sim \mathbf{A}_{44}$ are

$$
\begin{aligned}
\mathbf{H} & =\left[\begin{array}{llll}
H_{1} & H_{2} & \cdots & H_{N}
\end{array}\right]^{\mathrm{T}} \\
\mathbf{M} & =\left[\begin{array}{llll}
M_{1} & M_{2} & \cdots & M_{N}
\end{array}\right]^{\mathrm{T}} \\
\mathbf{V} & =\left[\begin{array}{llll}
V_{1} & V_{2} & \cdots & V_{N}
\end{array}\right]^{\mathrm{T}} \\
\mathbf{A}_{12} & =-\mathbf{A}_{21}^{\mathrm{T}}=\left[\begin{array}{cccc}
1 & 1 & \cdots & 1 \\
0 & 0 & \cdots & 0
\end{array}\right]_{2 \times N} \\
\mathbf{A}_{13} & =-\mathbf{A}_{31}^{\mathrm{T}}=\left[\begin{array}{cccc}
0 & 0 & \cdots & 0 \\
1 & 1 & \cdots & 1
\end{array}\right]_{2 \times N} \\
\mathbf{A}_{14} & =-\mathbf{A}_{41}^{\mathrm{T}}=\left[\begin{array}{cccc}
0 & 0 & \cdots & 0 \\
x_{1} & x_{2} & \cdots & x_{N}
\end{array}\right] \\
\mathbf{A}_{22} & =\left[\begin{array}{cccc}
\beta_{11}^{u H} & \beta_{12}^{u H} & \cdots & \beta_{1 N}^{u H} \\
\beta_{21}^{u H} & \beta_{22}^{u H} & \cdots & \beta_{2 N}^{u H} \\
\vdots & \vdots & \ddots & \vdots \\
\beta_{N 1}^{u H} & \beta_{N 2}^{u H} & \cdots & \beta_{N N}^{u H}
\end{array}\right] \\
\mathbf{A}_{23}= & {\left[\begin{array}{cccc}
\beta_{11}^{u M} & \beta_{12}^{u M} & \cdots & \beta_{1 N}^{u M} \\
\beta_{21}^{u M} & \beta_{22}^{u M} & \cdots & \beta_{2 N}^{u M} \\
\vdots & \vdots & \ddots & \vdots \\
\beta_{N 1}^{u M} & \beta_{N 2}^{u M} & \cdots & \beta_{N N}^{u M}
\end{array}\right] }
\end{aligned}
$$




$$
\begin{aligned}
& \mathbf{A}_{32}=\left[\begin{array}{cccc}
\beta_{11}^{\theta H} & \beta_{12}^{\theta H} & \cdots & \beta_{1 N}^{\theta H} \\
\beta_{21}^{\theta H} & \beta_{22}^{\theta H} & \cdots & \beta_{2 N}^{\theta H} \\
\vdots & \vdots & \ddots & \vdots \\
\beta_{N 1}^{\theta H} & \beta_{N 2}^{\theta H} & \cdots & \beta_{N N}^{\theta H}
\end{array}\right] \\
& \mathbf{A}_{33}=\left[\begin{array}{cccc}
\beta_{11}^{\theta M} & \beta_{12}^{\theta M} & \cdots & \beta_{1 N}^{\theta M} \\
\beta_{21}^{\theta M} & \beta_{22}^{\theta M} & \cdots & \beta_{2 N}^{\theta M} \\
\vdots & \vdots & \ddots & \vdots \\
\beta_{N 1}^{\theta M} & \beta_{N 2}^{\theta M} & \cdots & \beta_{N N}^{\theta M}
\end{array}\right] \\
& \mathbf{A}_{44}=\left[\begin{array}{cccc}
\beta_{11}^{V} & \beta_{12}^{V} & \cdots & \beta_{1 N}^{V} \\
\beta_{21}^{V} & \beta_{22}^{V} & \cdots & \beta_{2 N}^{V} \\
\vdots & \vdots & \ddots & \vdots \\
\beta_{N 1}^{V} & \beta_{N 2}^{V} & \cdots & \beta_{N N}^{V}
\end{array}\right] \\
& \beta_{k j}^{u H}=\alpha_{u u, k j}^{H} f_{u H}^{H}+\alpha_{u \theta, k j}^{H} f_{\theta H}^{H} \\
& \beta_{k j}^{u M}=\alpha_{u u, k j}^{H} f_{u M}^{H}+\alpha_{u \theta, k j}^{H} f_{\theta M}^{H} \\
& \beta_{k j}^{\theta H}=\alpha_{\theta u, k j}^{H} f_{u H}^{H}+\alpha_{\theta \theta, k j}^{H} f_{\theta H}^{H} \\
& \beta_{k j}^{\theta M}=\alpha_{\theta u, k j}^{H} f_{u M}^{H}+\alpha_{\theta \theta, k j}^{H} f_{\theta M}^{H} \\
& \beta_{k j}^{V}=\alpha_{k j}^{V} f^{V}
\end{aligned}
$$

where $k=1, \ldots, N$ and $j=1, \ldots, N$

According to the definition of the lateral impedance matrix, i.e.

$$
\mathbf{K}_{\mathbf{p}} \mathbf{u}^{\mathbf{G}}=\mathbf{P}^{\mathbf{G}}
$$

Through Eq. (14), the lateral impedance matrix of the pile group can be derived as

$$
\mathbf{K}_{\mathrm{p}}=\left(\mathbf{A}_{12}-\mathbf{A}_{13} \mathbf{A}_{23}^{-1} \mathbf{A}_{22}\right)\left(\mathbf{A}_{32}-\mathbf{A}_{33} \mathbf{A}_{23}^{-1} \mathbf{A}_{22}\right)^{-1}\left(\mathbf{A}_{33} \mathbf{A}_{23}^{-1} \mathbf{A}_{21}-\mathbf{A}_{31}\right)-\mathbf{A}_{13} \mathbf{A}_{23}^{-1} \mathbf{A}_{21}-\mathbf{A}_{14} \mathbf{A}_{44}^{-1} \mathbf{A}_{41} \text { (34) }
$$

\subsection{Determination of impedance matrix of caisson $\boldsymbol{K}_{\boldsymbol{c}}$}

The four-spring Winkler model proposed by Ref. [1] can be extendedly applied in the layer soils, as illustrated in Fig. 5. Herein, $d$ represents the embedment depth of the caisson, $d_{1} \sim d_{\mathrm{n}}$ are the thickness of the soil layers along the caisson shaft, and $h_{0}$ and $h_{1}$ are the distances from the center of gravity to the top surface and base surface of the caisson. Particularly when the caisson is fully embedded, the embedment depth of the caisson $d$ equals to its length $D$.

In frequency domain, when the caisson is subjected to the dynamic horizontal force $Q_{0}$ and moment $M_{0}$, the equilibrium of external loads, soil resistance and inertial forces with respect to the base center gives 


$$
\begin{gathered}
\mathbf{K}_{\mathbf{c}}\left\{\begin{array}{c}
u_{b} \\
\theta
\end{array}\right\}=\mathbf{P}_{\mathbf{b}} \\
\mathbf{K}_{\mathbf{c}}=-\omega^{2} \mathbf{M}_{\mathbf{b}}+\mathbf{K}_{\mathbf{b}}
\end{gathered}
$$

where, $\omega$ is the circular frequency, $u_{b}$ is the horizontal displacement of the base center and $\theta$ is the rotation angle. Load vector, mass matrix and complex stiffness matrix in above equations are respectively given by

$$
\begin{gathered}
\mathbf{P}_{\mathbf{b}}=\left\{\begin{array}{c}
Q_{0} \\
D Q_{0}+M_{0}
\end{array}\right\} \\
\mathbf{M}_{\mathbf{b}}=\left[\begin{array}{cc}
m & h_{1} m \\
h_{1} m & J+h_{1}^{2} m
\end{array}\right] \\
\mathbf{K}_{\mathbf{b}}=\left[\begin{array}{ll}
\widetilde{K}_{H H} & \widetilde{K}_{H M} \\
\widetilde{K}_{M H} & \widetilde{K}_{M M}
\end{array}\right]
\end{gathered}
$$

where, $m$ and $J$ are the mass and mass moment of inertia of the caisson about its center of gravity. By integration of the complex spring stiffness, each element of $\mathbf{K}_{\mathrm{b}}$ could be obtained as

$$
\begin{gathered}
\widetilde{K}_{H H}=\widetilde{K}_{h}+\sum_{i=1}^{n} \widetilde{k}_{x i} d_{i} \\
\widetilde{K}_{H M}=\widetilde{K}_{M H}=\sum_{i=1}^{n} \widetilde{k}_{x i} d_{i} z_{i} \\
\widetilde{K}_{M M}=\widetilde{K}_{r}+\sum_{i=1}^{n}\left[\widetilde{k}_{x i} d_{i}\left(z_{i}^{2}+\frac{1}{12} d_{i}^{2}\right)+\widetilde{k}_{\theta i} d_{i}\right]
\end{gathered}
$$

where $\tilde{k}_{x i}$ and $\tilde{k}_{\theta i}$ are the complex stiffness of the distributed translational and rotational springs (associated with dashpots) of layer $i$ ( $i$ varies from 1 to $n$ ), and $\tilde{K}_{h}$ and $\tilde{K}_{r}$ are the complex stiffness of the concentrated springs at the base, as shown in Fig. 5. For a CCPF, the soil deformation under the caisson part, induced by the deformation of the pile group, will lead to a huge loss of caisson base stiffness. Therefore, $\tilde{K}_{h}$ and $\tilde{K}_{r}$ should be neglected.

In Eq. (42), $z_{i}$ is the distance from the center of layer $i$ to the soil surface, i.e.

$$
z_{i}=d-\sum_{k=0}^{i-1} d_{k}-\frac{d_{i}}{2}
$$

The Winkler parameters $\tilde{k}_{x}$ and $\tilde{k}_{\theta}$ were back-determined in the study of Gerolymos and Gazetas [1], in which the impedance of caissons $\mathbf{K}_{\mathbf{b}}$ is approximated by the impedance of cylindrical embedded footings determined through Ref. [8]. 
According to the method, $\tilde{k}_{x}$ can be expressed as

$$
\begin{gathered}
\widetilde{k}_{x}=k_{x}^{\prime} k_{x, \text { static }}+\mathrm{i} \omega c_{x} \\
k_{x, \text { static }}=\frac{K_{H}\left(I_{t w}-1\right)}{d} \\
k_{x}^{\prime}=\frac{I_{t w} \chi_{e m b}-1}{I_{t w}-1}
\end{gathered}
$$

where $K_{H}$ is the static horizontal stiffness of circular surface footings, $I_{t w}$ is the horizontal embedment factor (the product of $K_{H}$ and $I_{t w}$ is the horizontal stiffness of embedded footings), and $\chi_{e m b}$ is the horizontal dynamic coefficient. The detailed expressions of $K_{H}, I_{t w}, \chi_{e m b}$ and $c_{x}$ can be determined by referring Refs. [1] and [8].

$\tilde{k}_{\theta}$ can be expressed as

$$
\begin{gathered}
\widetilde{k}_{\theta}=\widetilde{k}_{\theta 1}-\frac{1}{3} d^{2} \widetilde{k}_{x} \\
\widetilde{k}_{\theta 1}=k_{\theta 1}^{\prime} k_{\theta 1, \text { static }}+\mathrm{i} \omega c_{\theta 1} \\
k_{\theta 1, \text { static }}=\frac{K_{M}\left(\Gamma_{w}-1\right)}{d}
\end{gathered}
$$

where $K_{M}$ is the static rocking stiffness of circular surface footings, $\Gamma_{w}$ is the rocking embedment factor (the product of $K_{M}$ and $\Gamma_{w}$ is the rocking stiffness of embedded footings), and $k_{\theta 1}^{\prime}$ is the rocking dynamic coefficient. The detailed expressions of $K_{M}$, $\Gamma_{w}, k_{\theta 1}^{\prime}$ and $c_{\theta l}$ can be determined by refering Refs. [1] and [8].

Because of the difference of depth-width ratio between rigid caissons and shallow footings, it's necessary to check the accuracy of $I_{t w}$ and $\Gamma_{w}$ of shallow footings for their application in caissons, and a modification may be required if the accuracy is not satisfied. This work is given in Section 3.

\section{Modification and verification of the four-spring Winkler model for caissons}

\subsection{Modification of the embedment factors}

As introduced in Section 2.3, the expressions of the complex stiffness of the distributed springs in the four-spring Winkler model for caissons were determined by Gerolymos and Gazetas [1] based on the impedance of shallow footings. However, owing to the difference between the depth-width ratios of rigid caissons $(0.5 \leq d / B \leq 4)$ and those of shallow footings $(d / B \leq 1)$, the embedment factors, $I_{t w}$ and $\Gamma_{w}$ (in Eqs. (45) 
and (49)) should be checked, and some modification may be required for their utilization in caissons.

Varun [10] has computed the stiffness of some caissons by the finite element method for a wide range of $0.25 \leq d / B \leq 7$. Here those data with $d / B \leq 4$ are chosen to check and modify the parameters $I_{t w}$ and $\Gamma_{w}$.

According to Refs. [1] and [8], the horizontal embedment factor of a cylindrical caisson $I_{t w}$ has such relation with $d / B$

$$
I_{t w}=1+0.21\left(\frac{d}{B}\right)^{0.5}+1.43\left(\frac{d}{B}\right)^{0.8}+0.30\left(\frac{d}{B}\right)^{1.3}
$$

Varun's finite element simulations [10] computed the horizontal stiffness of caissons with respect to the top centers. These results are transformed to be the stiffness with respect to the base centers by coordinate transformation, and then divided by the stiffness of surface footings to obtain the embedment factors. Figure 6 shows the comparison of Eq. (50) against the data transformed from Varun's results. They match quite well, demonstrating that Eq. (50) is feasible to be used for the range of $0<d / B \leq 4$, and hence no modification is needed.

According to Refs. [1] and [8], the rocking embedment factor of a cylindrical caisson $\Gamma_{w}$ has such relation with $d / B$ as follows

$$
\Gamma_{w}=1+2.09\left(\frac{d}{B}\right)^{0.6}+5.18\left(\frac{d}{B}\right)^{2.5}
$$

Likewise, Varun's rocking stiffness of caissons with respect to the top centers [10] is transformed into the stiffness with respect to the base centers by coordinate transformation, and then divided by the rocking stiffness of surface footings to get the embedment factors. Comparison of Eq. (51) against the data transformed from Varun's finite element results are shown in Fig. 7, demonstrating that they agree well merely in the range of $d / B \leq 1$. Therefore, it is necessary to make a modification on Eq. (51) for applying it in the cases of $0<d / B \leq 4$. Keeping the exponents in Eq. (51) unchanged, and fitting the coefficients $A_{1}$ and $A_{2}$ of $\Gamma_{w}=1+A_{1}\left(\frac{d}{B}\right)^{0.6}+A_{2}\left(\frac{d}{B}\right)^{2.5}$ with data from Ref. [10] by the least square method, a new expression of $\Gamma_{w}$ is obtained as

$$
\Gamma_{w}=1+2.25\left(\frac{d}{B}\right)^{0.6}+7.01\left(\frac{d}{B}\right)^{2.5}
$$

The significance of this modification will bestudied in Section 3.2. 


\subsection{Verification by static and frequency domain finite element simulations}

In order to evaluate the significance of the above modification, comparisons between the modified four-spring Winkler model and 3D finite element method are conducted via three examples.

\subsubsection{Static response of a cylindrical caisson in homogenous soil}

The case presented here is a massless cylindrical caisson embedded in the homogenous soil and subjected to a static load. The diameter of the caisson, $B$, is $2 \mathrm{~m}$, and the depth, $d$, is a variable changing from 0 to $8 \mathrm{~m}$ (being a surface footing while $d=0$ ) rather than a constant, through which the influence of the ratio $d / B$ is studied. The Young's modulus, Poisson's ratio and the mass density of the soil are 1.0 MPa, 0.30 and $1600 \mathrm{~kg} / \mathrm{m}^{3}$ respectively. The horizontal static load applied at the top of the caisson is $1000 \mathrm{kN}$. A finite element model of the caisson and soil is created with 20-node solid elements. A quarter of the symmetric system is depicted in Fig. 8, where the model sizes are marked.

For an attempt to testify the significance of the modification on $\Gamma_{w}$, both four-spring Winkler models with unmodified $\Gamma_{w}$ (using Eq. (51)) and modified $\Gamma_{w}$ (using Eq. (52)) are applied and the results are compared against the finite element simulation. Horizontal displacements and rotation angles atop the caisson are shown in Fig. 9. The comparison between the finite element simulation and the unmodified Winkler model indicates that the difference becomes more conspicuous with the increase of the ratio $d / B$. Good agreements between the finite element simulation and the modified four-spring Winkler model show the significance of the modification on $\Gamma_{w}$.

\subsubsection{Dynamic response of a cylindrical caisson in homogenous soil}

Herein, the second case is conducted to compute the dynamic response of a caisson subjected to a horizontal harmonic load with the amplitude of $1000 \mathrm{kN}$ and the frequencies of $0 \sim 10 \mathrm{~Hz}$. The model is similar to that presented in Section 3.2.1, with the caisson depth $d$ set as $6 \mathrm{~m}$ and some soil elements changed into sponge boundary elements for wave absorption, The finite element mesh is shown in Fig. 10, where the soft grey elements enveloping the soil elements are the sponge boundary elements for attenuating the wave reflection.

Sponge boundary is one kind of absorption boundary proposed by Varun et al [9] and Varun [10] to attenuate the wave reflection at the boundary, of which the 
fundamental is the theory of viscoelasticity [20]. Taking the shear wave as example, as the wave propagates, the displacement in the visco-elastic media is

$$
u(x, t)=A_{0} e^{-\alpha x} e^{\mathrm{i} \omega\left(t-\frac{x}{c}\right)}
$$

where $x$ is the distance from the original point, $t$ is time, $\omega$ is circular frequency, $A_{0}$ is the amplitude at the original point and $c$ is the shear wave velocity. $e^{-\alpha x}$ indicates the attenuation of the amplitude. The values of $c$ and $\alpha$ depend on the visco-elastic material properties.

Sponge boundary can be made by adding Rayleigh damping to the boundary elements. Based on the fundamental, the Rayleigh damping parameters $a_{0}, a_{1}$ and boundary thickness $x$ in this example are determined as 10.5, 0.0105 and $12 \mathrm{~m}$.

Fig. 11 illustrates the results calculated by the four-spring Winkler model and 3D finite element simulation, and shows that the accuracy of the four-spring Winkler model is improved remarkably with the modification of $\Gamma_{w}$.

\subsubsection{Dynamic response of a cylindrical caisson in layered soils}

Here the dynamic response of a massless cylindrical caisson embedded in layered soils, as illustrated in Fig. 12, is studied as the third case. The diameter $B$ and the embedment depth $d$ of the caisson are $2 \mathrm{~m}$ and $8 \mathrm{~m}$. The top two soil layers have the thickness of $d_{1}=3 \mathrm{~m}$ and $d_{2}=4 \mathrm{~m}$, and the third layer is a half space. From the top to the bottom, the Young's moduli are $10 \mathrm{MPa}, 30 \mathrm{MPa}$ and $50 \mathrm{MPa}$ respectively, the mass densities are $1500 \mathrm{~kg} / \mathrm{m}^{3}, 1600 \mathrm{~kg} / \mathrm{m}^{3}$ and $1800 \mathrm{~kg} / \mathrm{m}^{3}$ respectively, and Poisson's ratio for all the three layers is 0.30 . The amplitude of the horizontal harmonic load atop the caisson is $1000 \mathrm{kN}$. This example was analyzed by Varun et al [9] by 3D finite element method. Here it is calculated with the four-spring Winkler model and the results are compared with the finite element results of Ref. [9]. As shown in Fig. 13, the comparison shows that the accuracy of the four-spring Winkler model in layered soils is improved remarkably with the modification of $\Gamma_{w}$.

The above three examples verify that the modification on $\Gamma_{w}$ is greatly significant to improve the accuracy of the spring coefficients for both static and dynamic loads and in both homogenous soil and layered soils.

\section{Lateral response of CCPFs: verification and example}

\subsection{Verification of the proposed method by $3 D$ FEM}


In order to verify the proposed method for lateral response of CCPFs, a series of numerical simulations are conducted and compared with the proposed method. The basic foundation is a rigid massless cylindrical caisson with depth-diameter ratio $d / B=1$ embedded in a homogenous soil half space. Besides the case of the caisson, two cases of CCPFs are considered by adding a $2 \times 2$ pile group and a $3 \times 3$ pile group beneath the caisson respectively. The foundations are all fully embedded, so their embedment depths equal to their lengths, namely $d=D$. The ratios between the piles and soils in terms of the Young's modulus, Poisson's ratio and the mass density are $E_{p} / E_{s}=1000, v_{p} / v_{s}=1$ and $\rho_{p} / \rho_{s}=1.25$. The pile length-caisson depth ratio, pile diameter-caisson diameter ratio and pile distance-pile diameter ratio are $L / d=2$, $2 r / B=0.1$ and $s / 2 r=5$ for the $2 \times 2$ pile group, and $L / d=2,2 r / B=0.1$ and $s / 2 r=2.5$ for the $3 \times 3$ pile group. In the numerical modeling, the caisson diameter, the soil Young's modulus, Poisson's ratio and mass density are set as $B=2 \mathrm{~m}, E_{s}=1 \mathrm{MPa}, v_{s}=0.30$ and $\rho_{s}=1600 \mathrm{~kg} / \mathrm{m}^{3}$ respectively. All the elements are modeled with 20 -nodes solid elements. A quarter of the symmetrical system of the soil and the CCPF with $3 \times 3$ pile group is depicted in Fig. 14, where the CCPF is shown in larger scale beside the total mesh. The cases of the caisson and the CCPF with $2 \times 2$ pile group have the same mesh with Fig. 14, with only the number of piles different.

The impedance of the caisson, the CCPF with $2 \times 2$ pile group and the CCPF with $3 \times 3$ pile group are all computed by the dynamic finite element method and the proposed simplified method (with $\Gamma_{w}$ modified). Figures $15 \sim 17$ give the normalized complex swaying stiffness, cross swaying-rocking stiffness and rocking stiffness of the caisson as functions of the dimensionless frequency respectively. The dimensionless frequency is given as

$$
a_{0}=\frac{\omega B}{2 V_{s}}
$$

where $V_{s}$ is the shear wave velocity of the soil.

Likewise, Figs. 18 20 are for the CCPF with $2 \times 2$ pile group while Figs. $21 \sim 23$ are for the $\mathrm{CCPF}$ with $3 \times 3$ pile group. In addition, the lateral response of these foundations under a harmonic horizontal load with the amplitude of $100 \mathrm{kN}$ is computed by both the numerical and simplified analytical methods, with the results shown in Fig. 24. These comparisons show that the simplified method agrees well with the numerical method, ensuring the reliability of the simplified method. 


\subsection{An example: lateral response of a CCPF with different pile lengths}

In order to study the significance of adding piles beneath the caisson, the response of a CCPF subjected to lateral harmonic loads is computed with the proposed method and the effect of pile length is studied. The diameter and the embedment depth of the caisson are $15 \mathrm{~m}$ and $20 \mathrm{~m}$. The caisson part is made of concrete, so its mass density is $2500 \mathrm{~kg} / \mathrm{m}^{3}$. Thickness of the top, bottom and side walls of the caisson is $1.0 \mathrm{~m}$. The pile part is a $3 \times 3$ steel-pipe pile group. The layout of these piles is shown in Fig. 25. The Young's modulus and mass density of the pile material are $206 \mathrm{GPa}$ and 7850 $\mathrm{kg} / \mathrm{m}^{3}$. The diameter of the piles is $80 \mathrm{~cm}$ and the wall thickness is $4 \mathrm{~cm}$. To study the pile length effect, the pile length is not a constant, and five sets of calculations are conducted with it varying among $0,10 \mathrm{~m}, 20 \mathrm{~m}, 40 \mathrm{~m}$ and $60 \mathrm{~m}$. The amplitudes of the harmonic horizontal load and moment atop the caisson are $10 \mathrm{MN}$ and $200 \mathrm{MN} \cdot \mathrm{m}$.

Two soil conditions are studied. In the first one, a homogeneous soil is adopted, of which the Young's modulus is $10 \mathrm{MPa}$, the mass density is $1500 \mathrm{~kg} / \mathrm{m}^{3}$ and the Poisson's ratio is 0.30 . In the second one, the soil below the caisson base and around the piles is changed to be stiffer by increasing its Young's Modulus and mass density to $30 \mathrm{MPa}$ and $1800 \mathrm{~kg} / \mathrm{m}^{3}$, forming a two-layer soil condition. Both conditions are computed and compared to show the effect of piles.

The impedances of the CCPF in both soil conditions and with all pile lengths are compared in Figs. 26 28, in which the results are normalized with the Young's Modulus of the homogeneous soil and the length of the caisson. The horizontal displacements and rocking angles atop the foundation are shown in Fig. 29 and Fig. 30 , for the two soil conditions respectively.

The results indicate that: (1) piles make great contribution to the foundation in resisting the lateral loads. The impedances of the foundation increase and the displacements decrease significantly after adding piles beneath the caisson; (2) although the soil around the caisson does not change, after the soil around the piles becomes stiffer, the impedances of the CCPF increase and the displacements decrease pronouncedly. This shows that in the composite foundation, the piles play an important role in resisting the lateral loads; (3) the increasing rate of the impedances and the decreasing rate of the displacements become smaller while the pile length becomes larger, showing that there is a limitation upon the pile length; and (4) piles have less impact on complex swaying stiffness than complex rocking stiffness. This is 
because under lateral loads the major response of the caisson is rocking effect, which can be largely resisted by the pile reaction forces.

From the third point above, it can be found that the lateral response of the CCPF could not be mitigated lastingly by solely increasing the pile length. If the pile length is large enough, the further increase of it will have only a small effect.

\section{Conclusions}

This paper proposed a simplified method for the lateral response of CCPFs based on the dynamic Winkler model. The main contribution of this paper includes: (1) the development of the modified four-spring Winkler model for caissons in layered soils, in which the rocking embedment factor $\Gamma_{w}$ is modified; (2) the derivation of the lateral impedance matrix for pile groups in layered soils; and (3) the combination of the caisson and piles that creates the Winkler model for lateral vibration of CCPFs.

For caissons, verifications by the finite element simulations show the significance of the modification on $\Gamma_{w}$ for both static and dynamic problems in both homogenous soil and layered soils. The proposed Winkler model for lateral response of CCPFs is also verified by the finite element method.

Finally, with the study of an example of the CCPF, it is concluded that adding piles is a significant way to increase the capability of the foundation in resisting the lateral dynamic loads. The effect of the pile length is also discussed. The lateral response of the CCPF could not be decreased lastingly only by increasing the pile length, so it is important to have a control on the pile length from the economic point of view.

\section{Appendix}

\section{A.1 The derivation of vertical vibration equation of pile group}

As given in Refs. [15] and [18], the axial vibration equation of a sole pile in soil layer $i$ is

$$
\frac{\mathrm{d}^{2} w_{i}(z)}{\mathrm{d} z^{2}}+\left(\frac{\lambda_{i}^{V}}{h_{i}}\right)^{2} w_{i}(z)=0
$$

where $z$ is the vertical coordinate, $w_{i}$ is the axial displacement of the pile, 
$\lambda_{i}^{V}=h_{i} \sqrt{\frac{m_{p} \omega^{2}-k_{p z i}-\mathrm{i} \omega c_{p z i}}{E_{p} A_{p}}}, h_{i}$ is the thickness of soil layer $i, m_{p}, E_{p}$ and $A_{p}$ are the distributed mass along the shaft, Young's Modulus and cross section area of the pile, $k_{p z i}$ and $c_{p z i}$ are the dynamic Winkler coefficients of soil layer $i$.

With the transfer matrix method, the relation of the axial displacements and forces between the pile top and bottom can be derived as

$$
\left\{\begin{array}{l}
w(L) \\
V(L)
\end{array}\right\}=\mathbf{T}_{\mathbf{v}}^{\mathbf{1}}\left\{\begin{array}{l}
w(0) \\
V(0)
\end{array}\right\}
$$

where $L$ is the pile length and $\mathbf{T}_{\mathbf{v}}^{1}$ is the axial transfer matrix. The axial flexibility of the sole pile $f^{V}\left(f^{V}=\frac{w(0)}{V(0)}\right)$ can then be determined with the boundary condition at the pile bottom.

To simulate the axial pile-pile interaction in layered soils, the axial vibration equation of a passive pile (e.g. pile 2) is given as

$$
\frac{\mathrm{d}^{2} w_{21, i}(z)}{\mathrm{d} z^{2}}+\left(\frac{\lambda_{i}^{V}}{h_{i}}\right)^{2} w_{21, i}(z)=-\frac{\left(k_{p z i}+\mathrm{i} \omega c_{p z i}\right) \psi_{i}^{V}(s) w_{11, i}(z)}{E_{p} A_{p}}
$$

where $w_{11, i}$ and $w_{21, i}$ are the axial displacements of the active and passive piles in soil layer $i$, and $\psi_{i}^{V}$ is the attenuation function of the axial displacement depending on the pile distance $s$.

With the transfer matrix method, the relation between the active and passive piles can be derived as

$$
\left\{\begin{array}{l}
w_{21}(L) \\
V_{21}(L)
\end{array}\right\}=\mathbf{T}_{\mathbf{V}}^{\mathbf{1}}\left\{\begin{array}{l}
w_{21}(0) \\
V_{21}(0)
\end{array}\right\}+\mathbf{T}_{\mathbf{v}}^{\mathbf{2}}\left\{\begin{array}{l}
w_{11}(0) \\
V_{11}(0)
\end{array}\right\}
$$

where $\mathbf{T}_{\mathbf{v}}^{2}$ is the axial inter-transfer matrix between the two piles. The axial pile-pile interaction $\alpha^{V}\left(\alpha^{V}=\frac{w_{21}(0)}{w_{11}(0)}\right)$ can then be determined with the boundary condition at the pile bottom.

Considering the effects from all other piles, the axial displacement at the head of a pile (e.g. pile $k$ ) in a pile group can be obtained by

$$
w_{k}=\sum_{j=1}^{N} \alpha_{k j}^{V} f^{V} V_{j}, \quad k=1 \cdots N
$$

where $N$ is the number of the piles, $V_{j}$ is the axial load undertaken by pile $j$, and $\alpha_{k j}^{V}$ is the axial pile-pile interaction factor between pile $j$ and pile $k$. 
As given in Refs. [16] and [19], the lateral vibration equation of a sole pile in soil layer $i$ is

$$
\frac{\mathrm{d}^{4} u_{i}(z)}{\mathrm{d} z^{4}}-\left(\frac{\lambda_{i}^{H}}{h_{i}}\right)^{4} u_{i}(z)=0
$$

where $u_{i}$ is the horizontal displacement, $\lambda_{i}^{H}=h_{i}\left(\frac{m_{p} \omega^{2}-k_{p x i}-\mathrm{i} \omega c_{p x i}}{E_{p} I_{p}}\right)^{\frac{1}{4}}, I_{p}$ is the cross section moment of inertial of the pile, $k_{p x i}$ and $c_{p x i}$ are the horizontal dynamic Winkler coefficients of soil layer $i$.

The relation of the lateral displacements and forces between the pile top and bottom can be derived through the transfer matrix method, i.e.

$$
\left\{\begin{array}{c}
u(L) \\
\theta(L) \\
H(L) \\
M(L)
\end{array}\right\}=\mathbf{T}_{\mathbf{H}}^{\mathbf{1}}\left\{\begin{array}{c}
u(0) \\
\theta(0) \\
H(0) \\
M(0)
\end{array}\right\}
$$

where $\theta$ is the rotation angle, $H$ and $M$ are the shear force and the moment in the pile, and $\mathbf{T}_{\mathbf{H}}^{\mathbf{1}}$ is the lateral transfer matrix.

The lateral flexibility matrix of the sole pile $\mathbf{f}^{\mathbf{H}}\left(\left\{\begin{array}{l}u(0) \\ \theta(0)\end{array}\right\}=\mathbf{f}^{\mathbf{H}}\left\{\begin{array}{l}H(0) \\ M(0)\end{array}\right\}\right)$ can then be determined with the boundary condition at the pile bottom.

The lateral vibration equation of a passive pile (e.g. pile 2) is given as

$$
\frac{\mathrm{d}^{4} u_{21, i}(z)}{\mathrm{d} z^{4}}-\left(\frac{\lambda_{i}^{H}}{h_{i}}\right)^{4} u_{21, i}(z)=\frac{\left(k_{p x i}+\mathrm{i} \omega c_{p x i}\right) \psi_{i}^{H}(s, \varphi) u_{11, i}(z)}{E_{p} I_{p}}
$$

where $u_{11, i}$ and $u_{21, i}$ are the horizontal displacements of the active and passive piles in soil layer $i$, and $\psi_{i}^{H}$ is the attenuation function of horizontal displacement depending on the pile distance $s$ and the angle $\varphi$ between the oscillating and displacement directions.

With the transfer matrix method the relation of the lateral displacements and forces between the active and passive piles can be derived as

$$
\left\{\begin{array}{c}
u_{21}(L) \\
\theta_{21}(L) \\
H_{21}(L) \\
M_{21}(L)
\end{array}\right\}=\mathbf{T}_{\mathbf{H}}^{\mathbf{1}}\left\{\begin{array}{c}
u_{21}(0) \\
\theta_{21}(0) \\
H_{21}(0) \\
M_{21}(0)
\end{array}\right\}+\mathbf{T}_{\mathbf{H}}^{\mathbf{2}}\left\{\begin{array}{c}
u_{11}(0) \\
\theta_{11}(0) \\
H_{11}(0) \\
M_{11}(0)
\end{array}\right\}
$$


where $\mathbf{T}_{\mathbf{H}}^{2}$ is the lateral inter-transfer matrix between the two piles. The pile-pile interaction matrix of lateral vibration $\boldsymbol{\alpha}^{\mathbf{H}}\left(\left\{\begin{array}{l}u_{21}(0) \\ \theta_{21}(0)\end{array}\right\}=\boldsymbol{\alpha}^{\mathbf{H}}\left\{\begin{array}{l}u_{11}(0) \\ \theta_{11}(0)\end{array}\right\}\right)$ can then be determined with the boundary condition at the pile bottom.

Considering the effects from all other piles, the lateral displacements at the head of a pile (e.g. pile $k$ ) in a pile group can be obtained by

$$
\left\{\begin{array}{l}
u_{k} \\
\theta_{k}
\end{array}\right\}=\sum_{j=1}^{N}\left(\boldsymbol{\alpha}_{\mathbf{k j}}^{\mathbf{H}} \mathbf{H}^{\mathbf{H}}\left\{\begin{array}{l}
H_{j} \\
M_{j}
\end{array}\right\}\right)=\sum_{j=1}^{N}\left(\left[\begin{array}{cc}
\alpha_{u u, k j}^{H} & \alpha_{u \theta, k j}^{H} \\
\alpha_{\theta u, k j}^{H} & \alpha_{\theta \theta, k j}^{H}
\end{array}\right]\left[\begin{array}{cc}
f_{u H}^{H} & f_{u M}^{H} \\
f_{\theta H}^{H} & f_{\theta M}^{H}
\end{array}\right]\left\{\begin{array}{c}
H_{j} \\
M_{j}
\end{array}\right\}\right)
$$

where $H_{j}$ and $M_{j}$ are the horizontal load and moment undertaken by pile $j$, and $\boldsymbol{\alpha}_{\mathbf{k j}}^{\mathbf{H}}$ is the lateral pile-pile interaction matrix between pile $j$ and pile $k$.

\section{Acknowledgement}

This work was supported by Natural Science Foundation of China with Grant No. 90915011.

\section{Reference}

[1] Gerolymos N, Gazetas G. Winkler model for lateral response of rigid caisson foundations in linear soil. Soil Dyn Earthq Eng 2006; 26(5): 347-61.

[2] Gerolymos N, Gazetas G. Development of Winkler model for static and dynamic response of caisson foundations with soil and interface nonlinearities. Soil Dyn Earthq Eng 2006; 26(5): 363-76.

[3] Gerolymos N, Gazetas G. Static and dynamic response of massive caisson foundations with soil and interface nonlinearities — validation and results. Soil Dyn Earthq Eng 2006; 26(5): 377-94.

[4] Gazetas G, Tassoulas JL. Horizontal stiffness of arbitrarily shaped embedded foundations. J Geotech Eng, ASCE 1987; 113(5): 440-57.

[5] Gazetas G, Tassoulas JL. Horizontal damping of arbitrarily shaped embedded foundations. J Geotech Eng, ASCE 1987; 113(5): 458-75.

[6] Hatzikonstantinou E, Tassoulas JL, Gazetas G, Kotsanopoulos P, Fotopoulou M. Rocking stiffness of arbitrarily shaped embedded foundations. J Geotech Eng, ASCE 1989; 115(4): 457-72.

[7] Fotopoulou M, Kotsanopoulos P, Gazetas G, Tassoulas JL. Rocking damping of arbitrarily-shaped embedded foundations[J]. J Geotech Eng, ASCE 1989; 115(4): 473-89.

[8] Gazetas G. Formulas and charts for impedances of surface and embedded foundations. J Geotech Eng, ASCE 1991; 117(9): 1363-81.

[9] Varun, Assimaki D, Gazetas G. A simplified model for lateral response of large diameter caisson foundations - Linear elastic formulation. Soil Dyn Earthq Eng 2009; 29(2): 268-91. 
[10] Varun. A simplified model for lateral response of caisson foundations. Athens, Greece: Georgia Institute of Technology, 2006.

[11] Tsigginos C, Gerolymos N, Assimaki D, Gazetas G. Seismic response of bridge pier on rigid caisson foundation in soil stratum. Earthq Eng Eng Vibr 2008; 7(1): 33-44.

[12] Beredugo YO, Novak M. Coupled horizontal and rocking vibration of embedded footings. Can Geotech J 1972; 9: 477-93.

[13] Kausel E, Roësset JM. Dynamic stiffness of circular foundations. J Eng Mech Div, ASCE 1975; 101(6):771-84.

[14] Wolf JP. Spring-dashpot-mass models for foundation vibration. Earthq Eng Struct Dyn 1997; 26(9): 931-49.

[15] Gazetas G, Makris N. Dynamic pile-soil-pile interaction. Part I: Analysis of axial vibration. Earthq Eng Struct Dyn 1991; 20: 115-32.

[16] Makris N, Gazetas G. Dynamic pile-soil-pile interaction. Part II: Lateral and seismic response. Earthq Eng Struct Dyn 1992; 21: 145-62.

[17] Mylonakis G, Gazetas G. Lateral vibration and internal forces of grouped piles in layered soil. J Geotech Geoenviron Eng ASCE 1999; 125(1): 16-25.

[18] Wu ZM, Huang MS, Ren Q. Vertical vibration and internal forces of pile groups in layered soil. Journal of Tongji University (Natural Science) 2007; 35(1): 21-26. (in Chinese)

[19] Huang MS, Wu ZM, Ren Q. Lateral vibration of pile groups in layered soil. Chinese Journal of Geotechnical Engineering 2007; 29(1): 32-38. (in Chinese)

[20] Christensen RM. Theory of viscoelasticity: An introduction, second edition. Academic press, New York, 1982. 


\section{Figure captions}

Fig. 1 Schematic diagram of the composite caisson-piles foundation.

Fig. 2. Winkler model for lateral vibration of the composite caisson-piles foundation.

Fig. 3. Vertical response of piles when the CCPF rotates

Fig. 4. Axial-lateral coupled vibration of the pile group with rigid cap subjected to vertical, horizontal and moment loads.

Fig. 5. Four-spring Winkler model for lateral vibration of the caisson in layered soils.

Fig. 6. Horizontal embedment factors of cylindrical rigid caissons.

Fig. 7. Rocking embedment factors of cylindrical rigid caissons.

Fig. 8. Finite element mesh for static analyses of a cylindrical caisson in homogeneous soil.

Fig. 9. Static horizontal displacements and rotation angles of a cylindrical caisson in homogeneous soil.

Fig. 10. Finite element mesh for dynamic analyses of a cylindrical caisson in homogeneous soil.

Fig. 11. Horizontal displacements and rotation angles in frequency domain of a cylindrical caisson in homogeneous soil.

Fig. 12. Schematic diagram of a cylindrical caisson in layered soils.

Fig. 13. Horizontal displacements and rotation angles in frequency domain of a cylindrical caisson in layered soils.

Fig. 14. Finite element mesh for dynamic analyses of CCPFs and a caisson in homogenous soil.

Fig. 15. Normalized complex swaying stiffness atop the caisson in the homogenous soil.

Fig. 16. Normalized complex cross swaying-rocking stiffness atop the caisson in the homogenous soil.

Fig. 17. Normalized complex rocking stiffness atop the caisson in the homogenous soil.

Fig. 18. Normalized complex swaying stiffness atop the CCPF with $2 \times 2$ pile group in the homogenous soil.

Fig. 19. Normalized complex cross swaying-rocking stiffness atop the CCPF with $2 \times 2$ pile group in the homogenous soil. 
Fig. 20. Normalized complex rocking stiffness atop the CCPF with $2 \times 2$ pile group in the homogenous soil.

Fig. 21. Normalized complex swaying stiffness atop the CCPF with $3 \times 3$ pile group in the homogenous soil.

Fig. 22. Normalized complex cross swaying-rocking stiffness atop the CCPF with $3 \times 3$ pile group in the homogenous soil.

Fig. 23. Normalized complex rocking stiffness atop the CCPF with $3 \times 3$ pile group in the homogenous soil.

Fig. 24. Horizontal displacements and rotation angles of the caisson and the CCPFs in the homogenous soil.

Fig. 25. The layout of the piles beneath the caisson and the geometric attribute of the CCPF from the side view.

Fig. 26. Normalized complex swaying stiffness atop the CCPF.

Fig. 27. Normalized complex cross swaying-rocking stiffness atop the CCPF.

Fig. 28. Normalized complex rocking stiffness atop the CCPF.

Fig. 29. Horizontal displacements and rotation angles of the CCPF in homogeneous soil.

Fig. 30. Horizontal displacements and rotation angles of the CCPF with stiffer soil around the piles. 


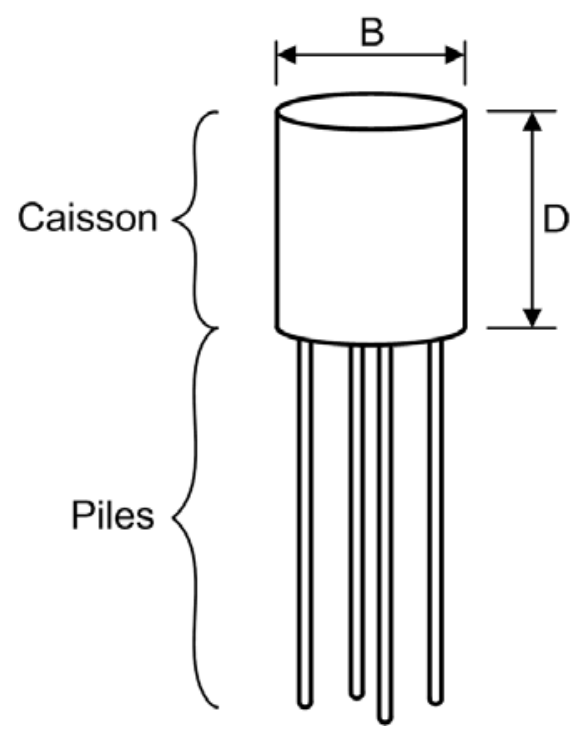

Fig. 1 Schematic diagram of the composite caisson-piles foundation.

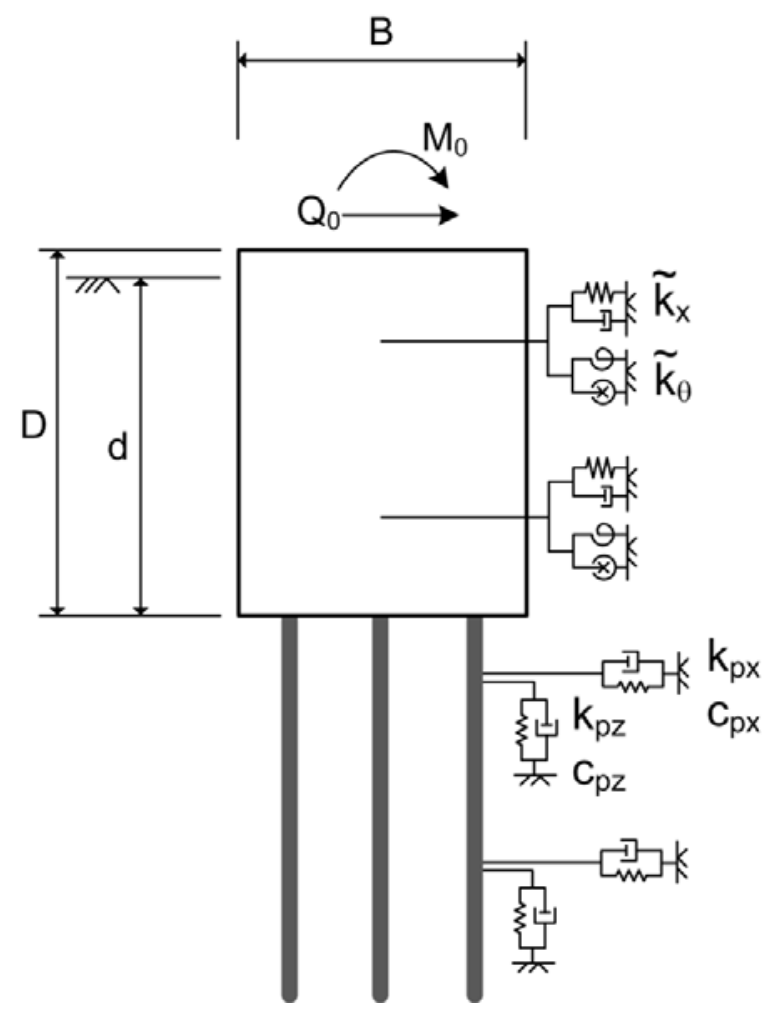

Fig. 2. Winkler model for lateral vibration of the composite caisson-piles foundation. 


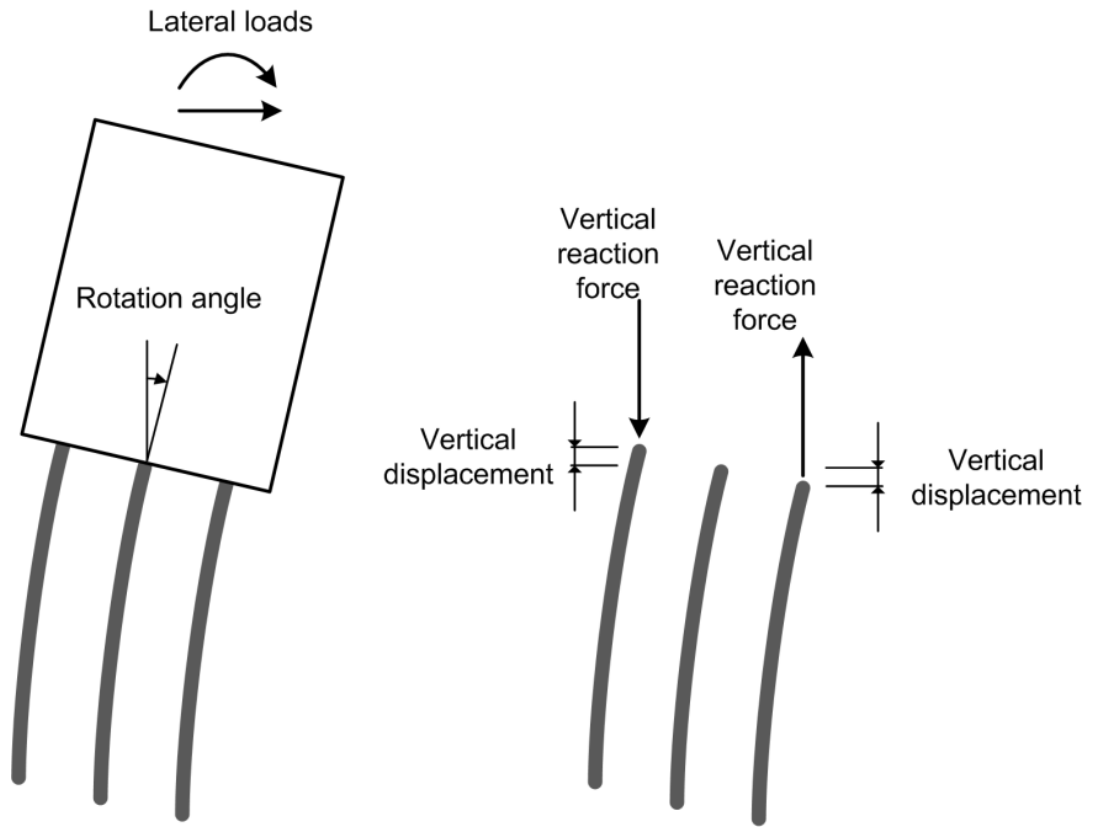

Fig. 3. Vertical response of piles when the CCPF rotates

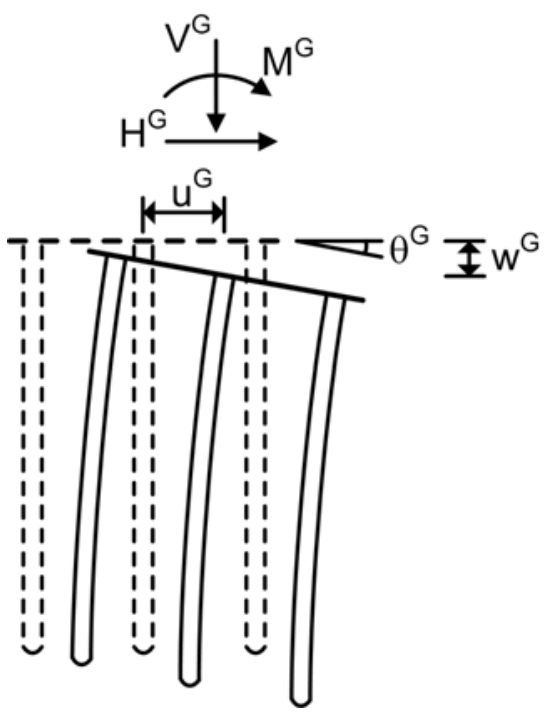

Fig. 4. Axial-lateral coupled vibration of the pile group with rigid cap subjected to vertical, horizontal and moment loads. 


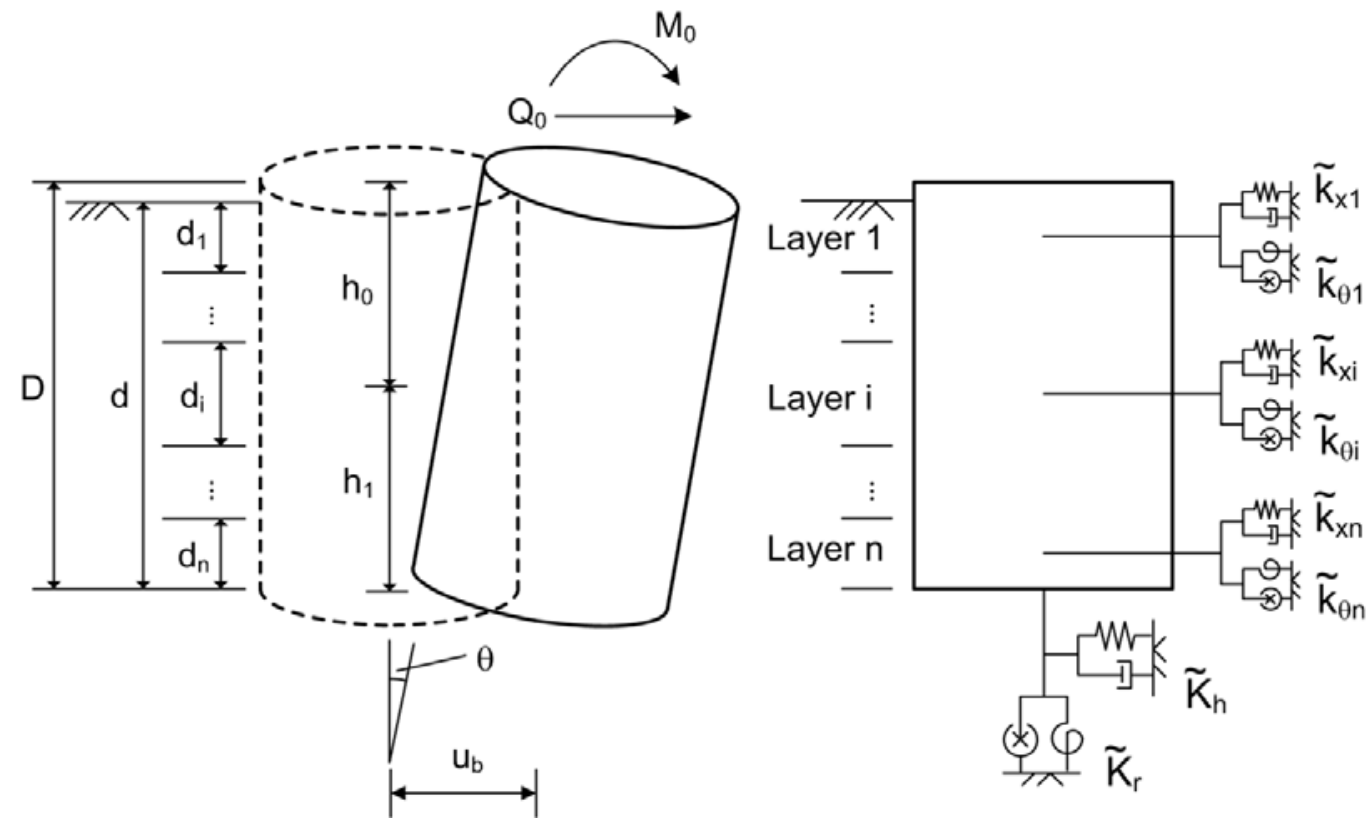

Fig. 5. Four-spring Winkler model for lateral vibration of the caisson in layered soils.

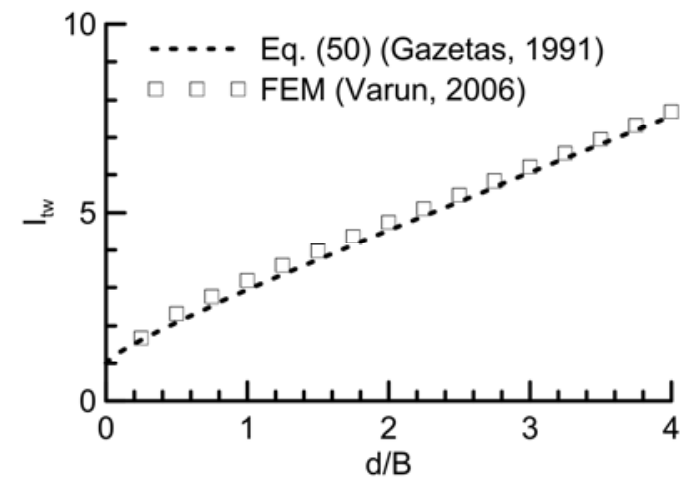

Fig. 6. Horizontal embedment factors of cylindrical rigid caissons.

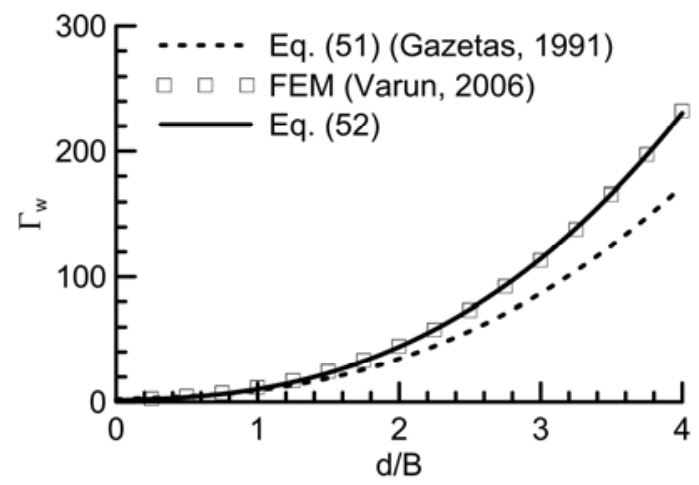

Fig. 7. Rocking embedment factors of cylindrical rigid caissons. 


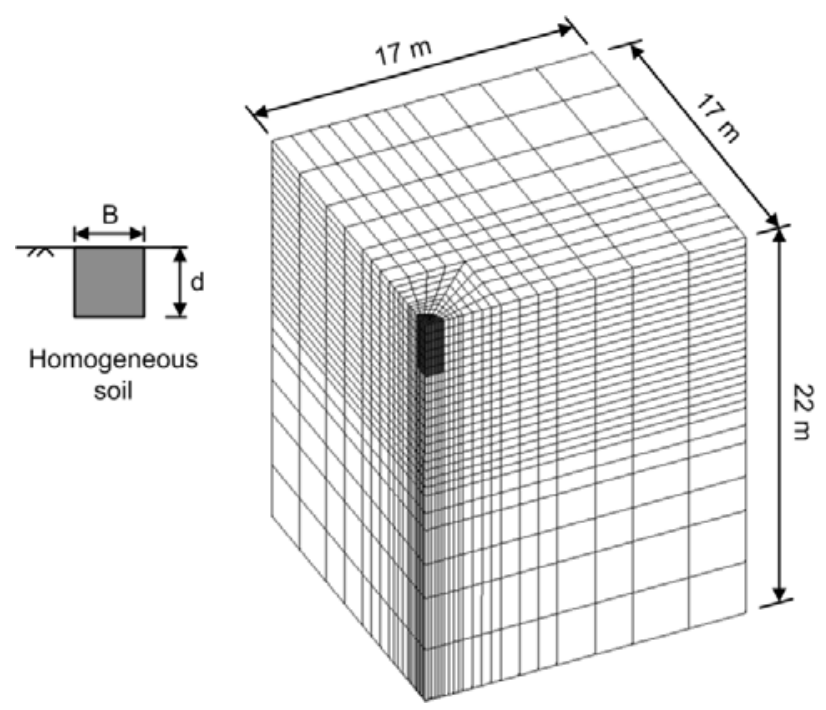

Fig. 8. Finite element mesh for static analyses of a cylindrical caisson in homogeneous soil.

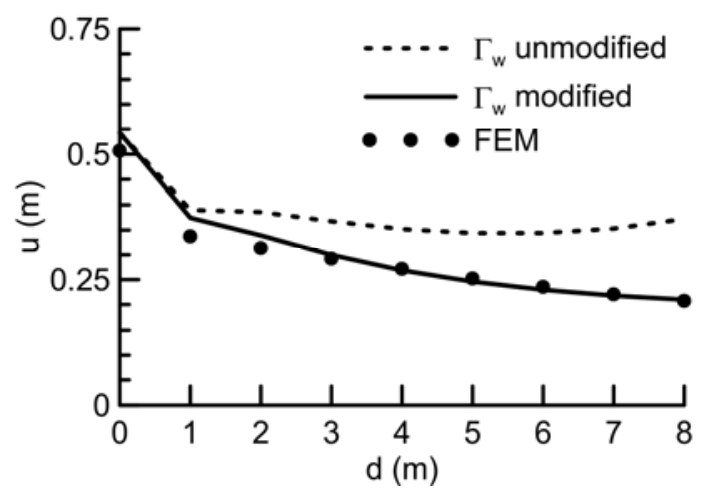

(a) Horizontal displacements

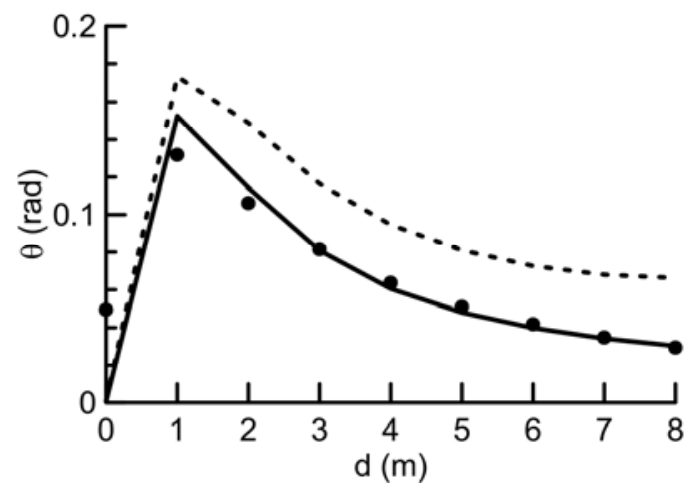

(b) Rotation angles

Fig. 9. Static horizontal displacements and rotation angles of a cylindrical caisson in homogeneous soil. 


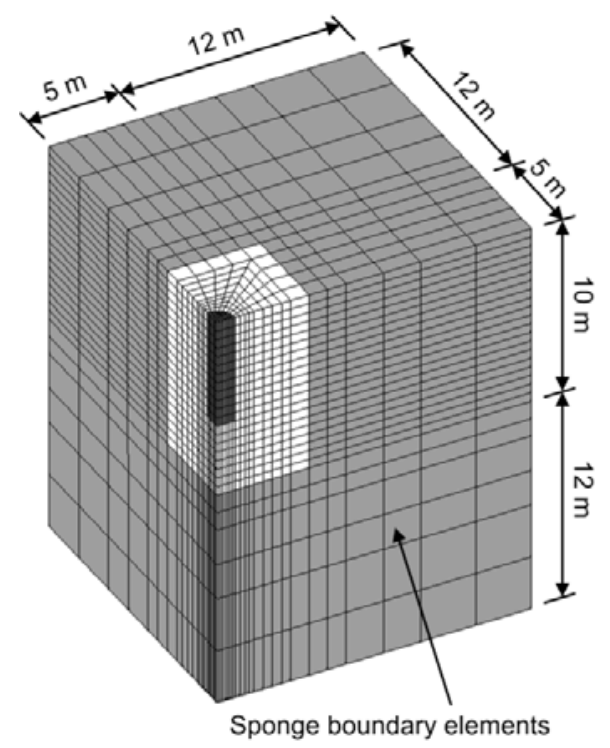

Fig. 10. Finite element mesh for dynamic analyses of a cylindrical caisson in homogeneous soil.

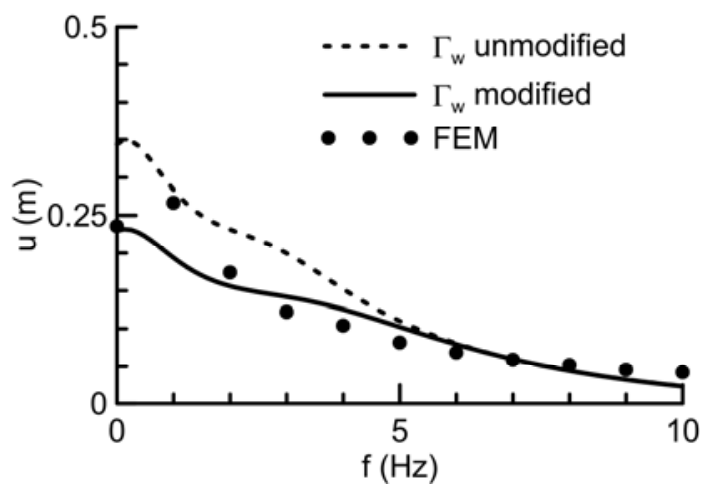

(a) Horizontal displacements

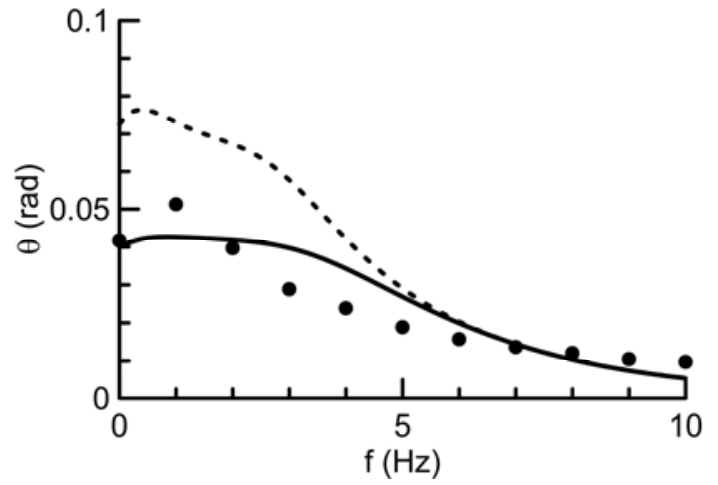

(b) Rotation angles

Fig. 11. Horizontal displacements and rotation angles in frequency domain of a cylindrical caisson in homogeneous soil. 


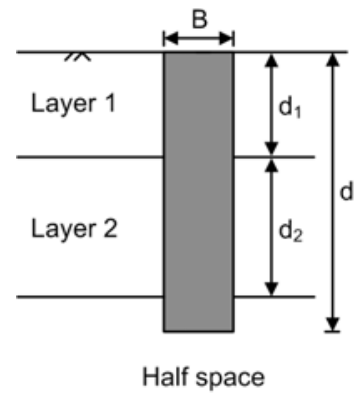

Fig. 12. Schematic diagram of a cylindrical caisson in layered soils.

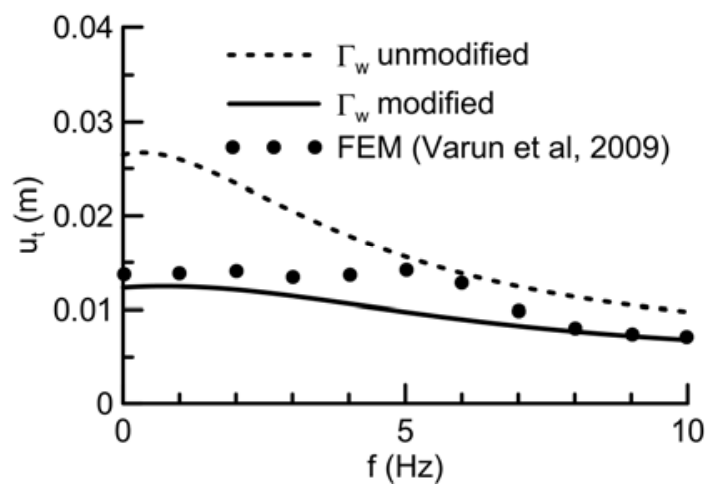

(a) Horizontal displacements

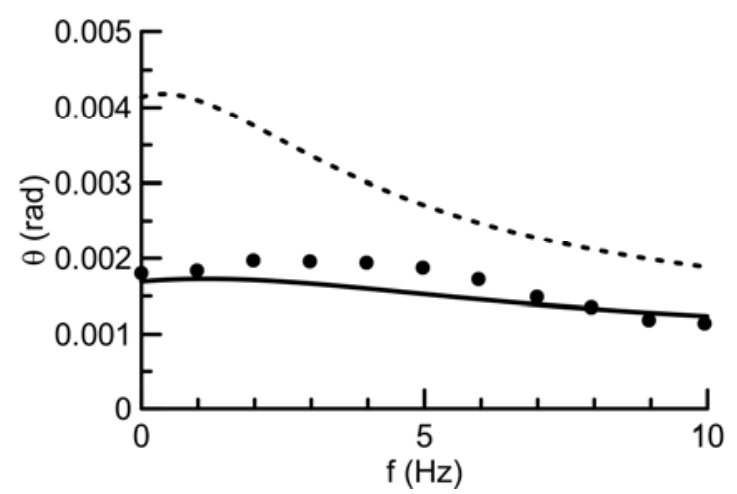

(b) Rotation angles

Fig. 13. Horizontal displacements and rotation angles in frequency domain of a cylindrical caisson in layered soils. 


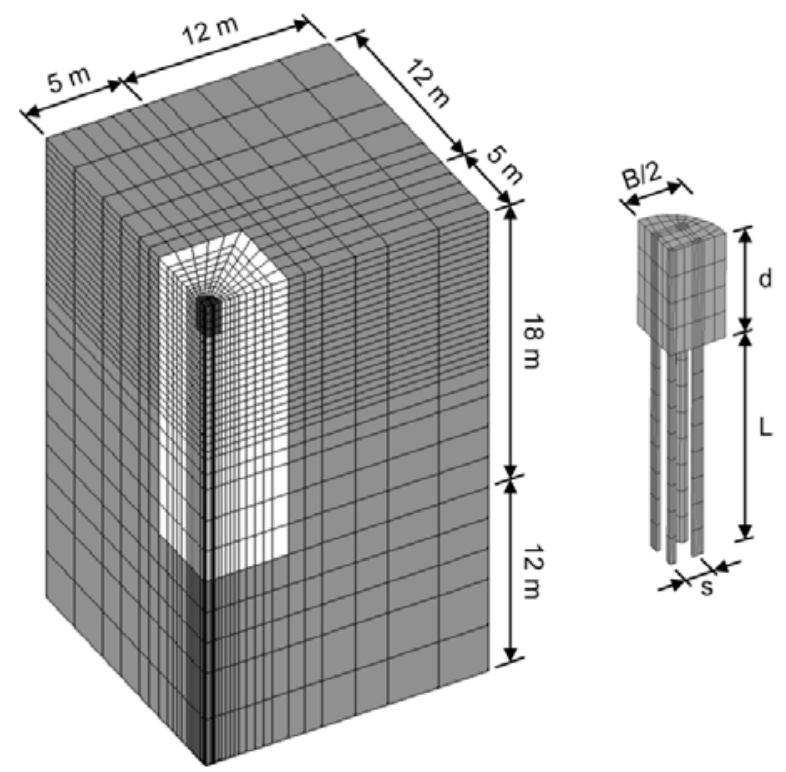

Fig. 14. Finite element mesh for dynamic analyses of CCPFs and a caisson in homogenous soil.

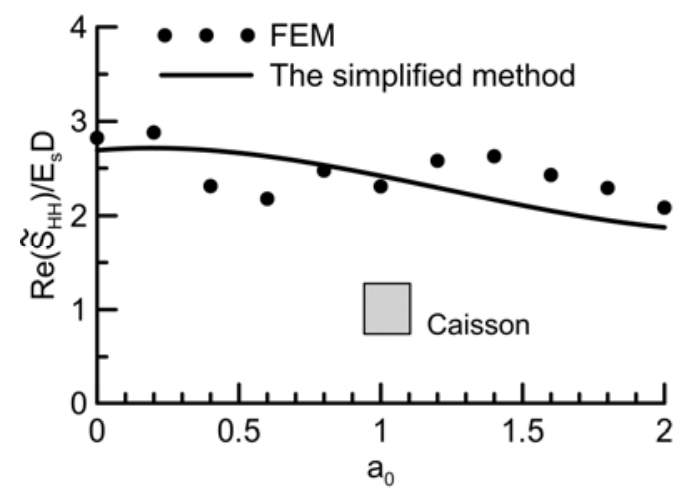

(a) Real part

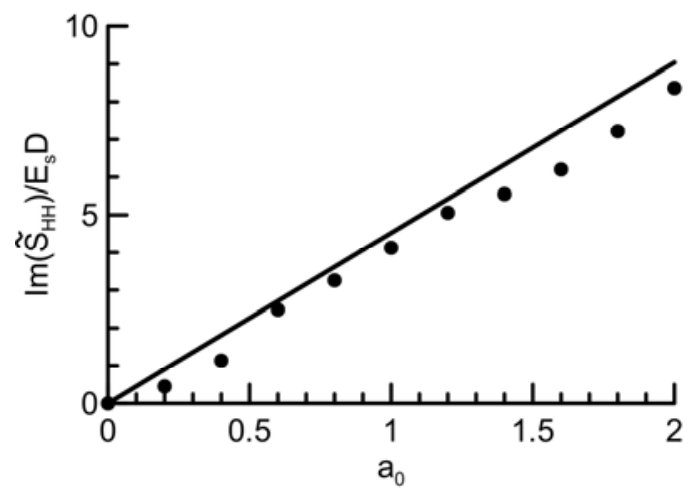

(b) Imaginary part

Fig. 15. Normalized complex swaying stiffness atop the caisson in the homogenous soil. 


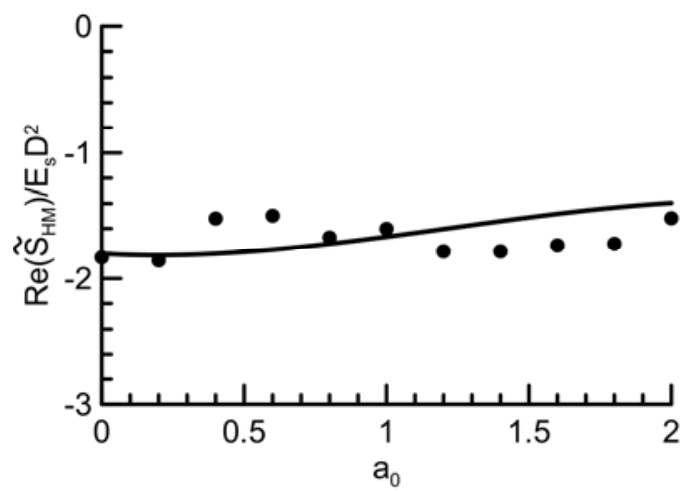

(a) Real part

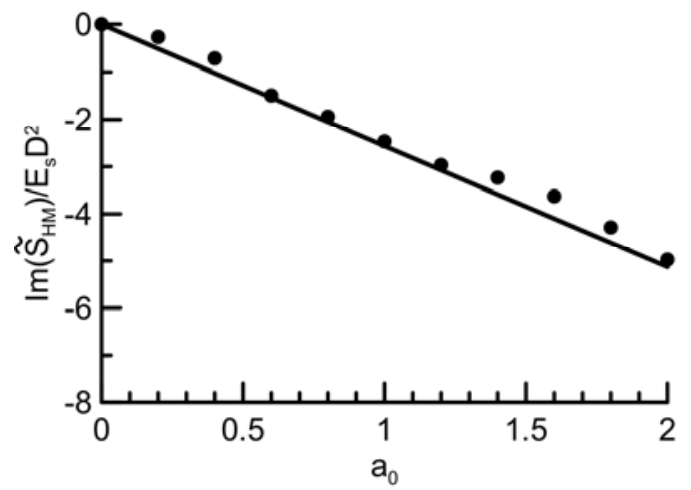

(b) Imaginary part

Fig. 16. Normalized complex cross swaying-rocking stiffness atop the caisson in the homogenous soil.

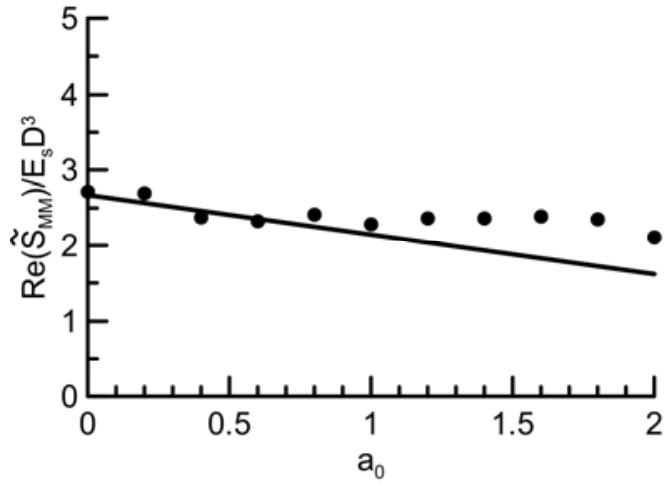

(a) Real part 


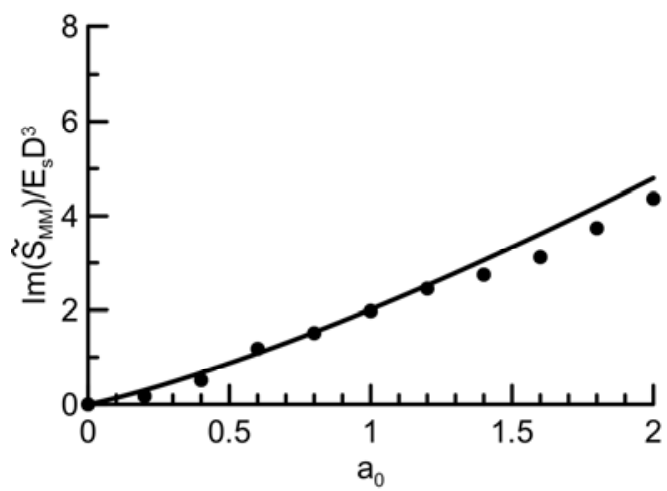

(b) Imaginary part

Fig. 17. Normalized complex rocking stiffness atop the caisson in the homogenous soil.

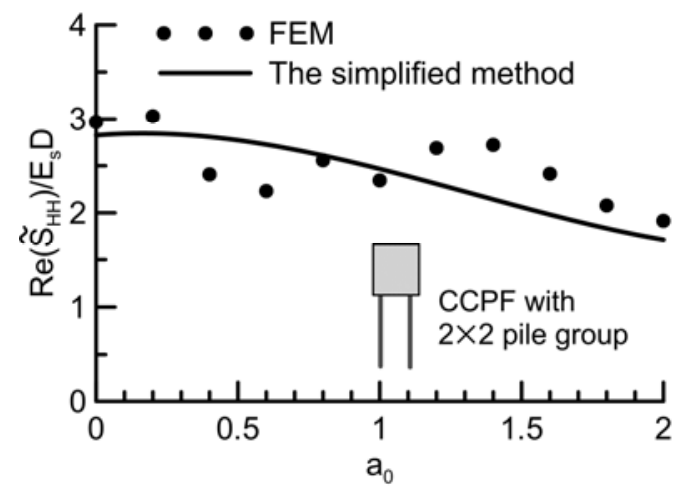

(a) Real part

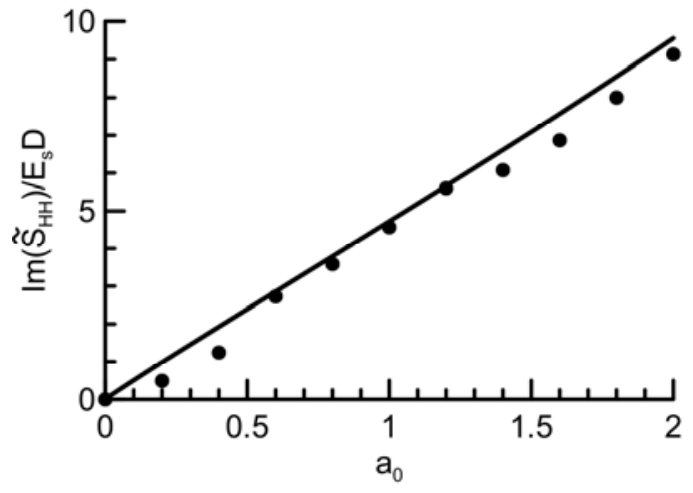

(b) Imaginary part

Fig. 18. Normalized complex swaying stiffness atop the CCPF with $2 \times 2$ pile group in the homogenous soil. 


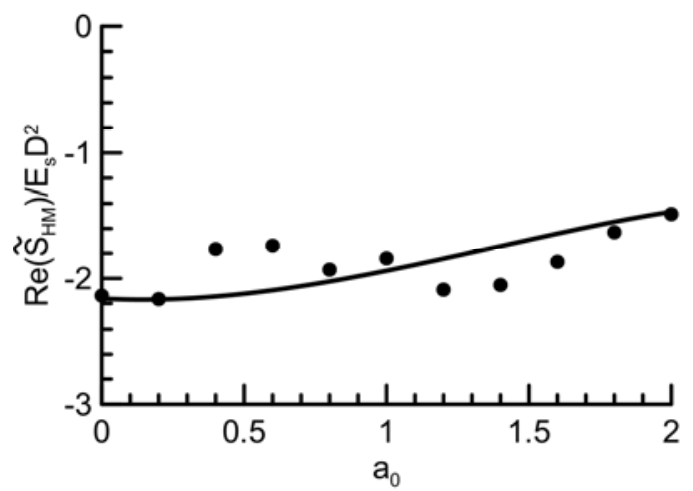

(a) Real part

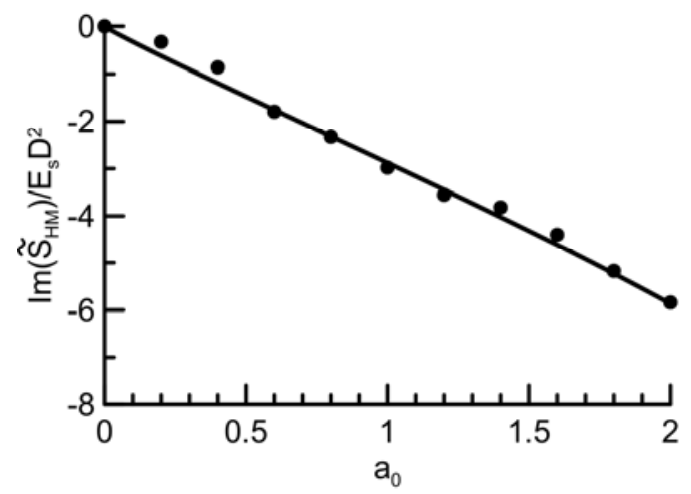

(b) Imaginary part

Fig. 19. Normalized complex cross swaying-rocking stiffness atop the CCPF with $2 \times 2$ pile group in the homogenous soil.

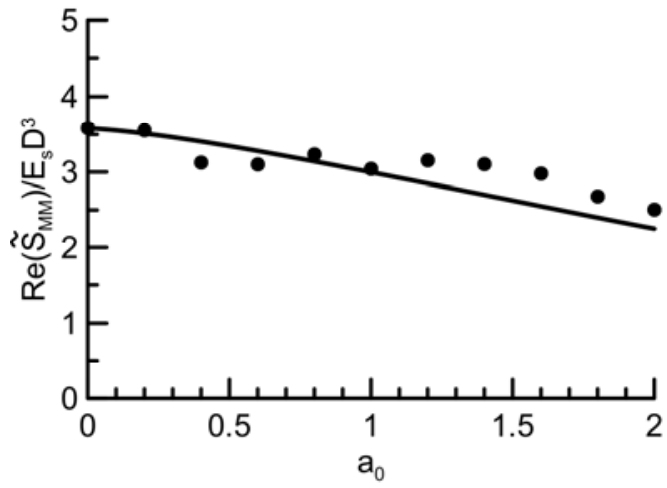

(a) Real part 


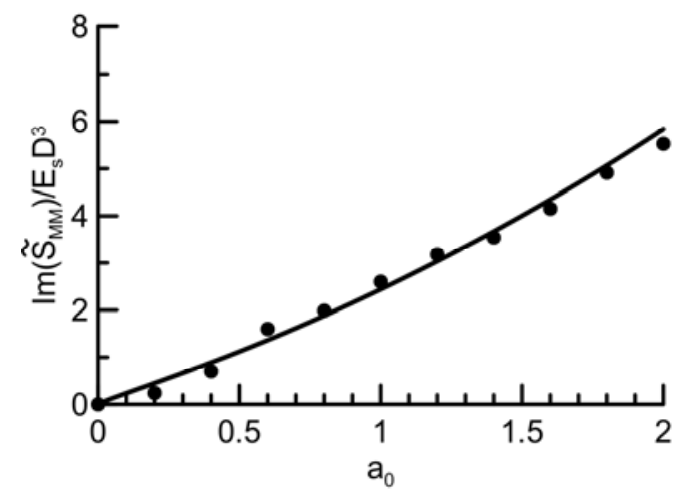

(b) Imaginary part

Fig. 20. Normalized complex rocking stiffness atop the CCPF with $2 \times 2$ pile group in the homogenous soil.

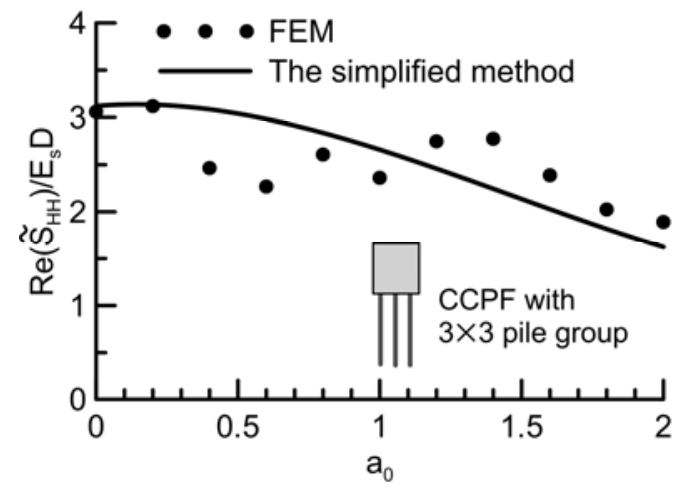

(a) Real part

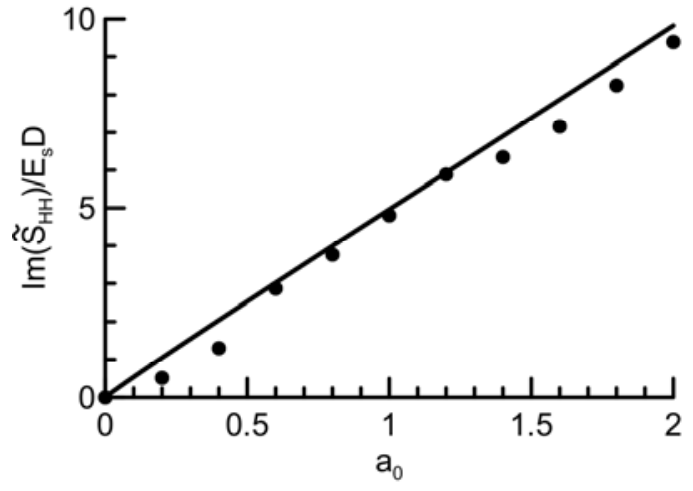

(b) Imaginary part

Fig. 21. Normalized complex swaying stiffness atop the CCPF with $3 \times 3$ pile group in the homogenous soil. 


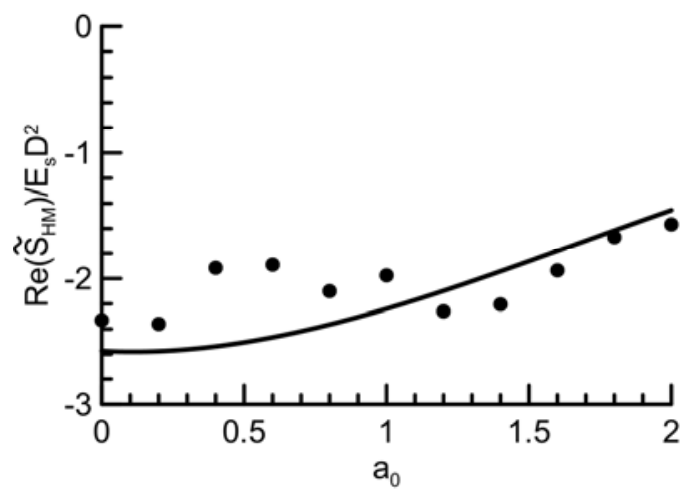

(a) Real part

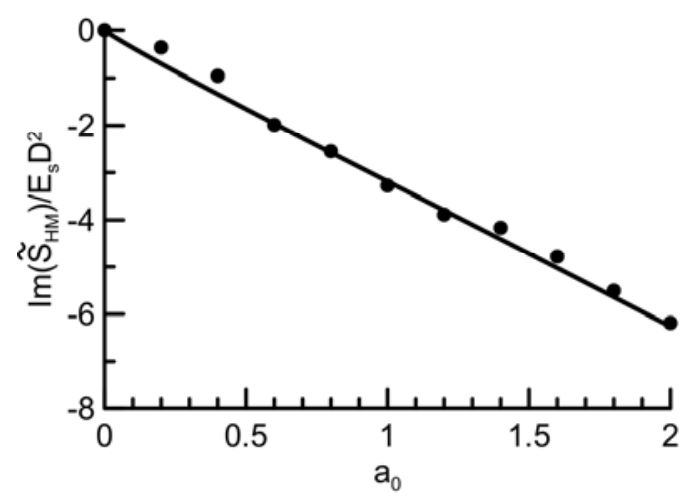

(b) Imaginary part

Fig. 22. Normalized complex cross swaying-rocking stiffness atop the CCPF with $3 \times 3$ pile group in the homogenous soil.

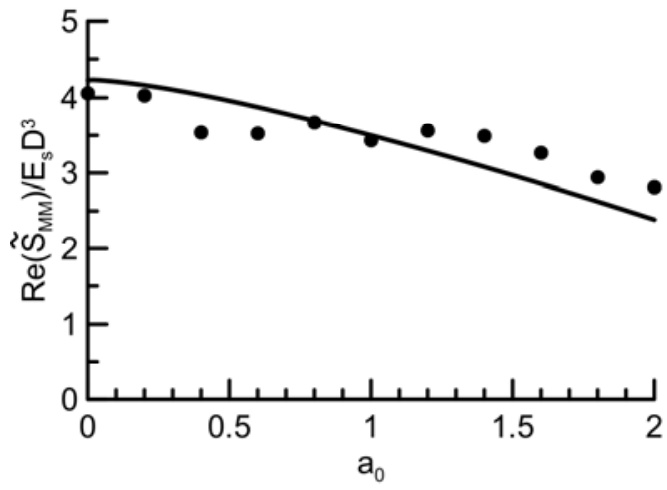

(a) Real part 


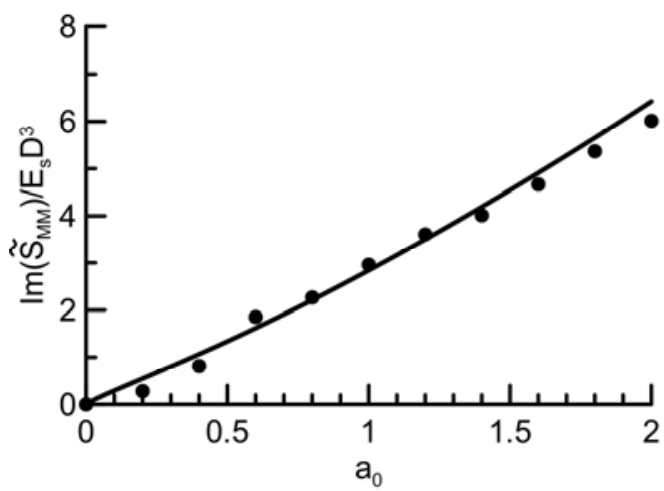

(b) Imaginary part

Fig. 23. Normalized complex rocking stiffness atop the CCPF with $3 \times 3$ pile group in the homogenous soil.

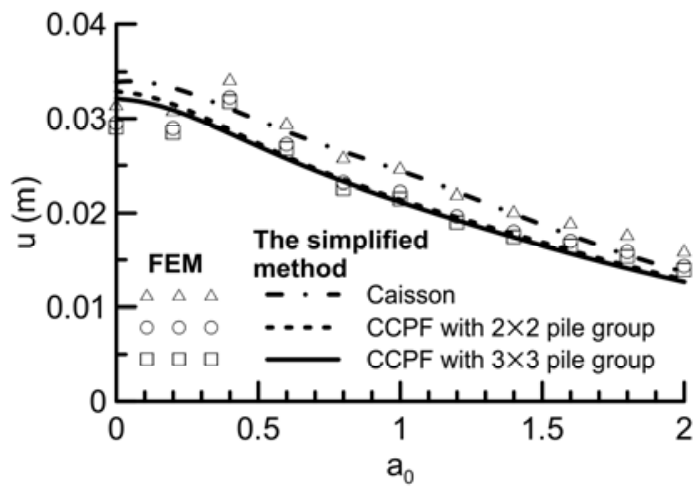

(a) Horizontal displacements

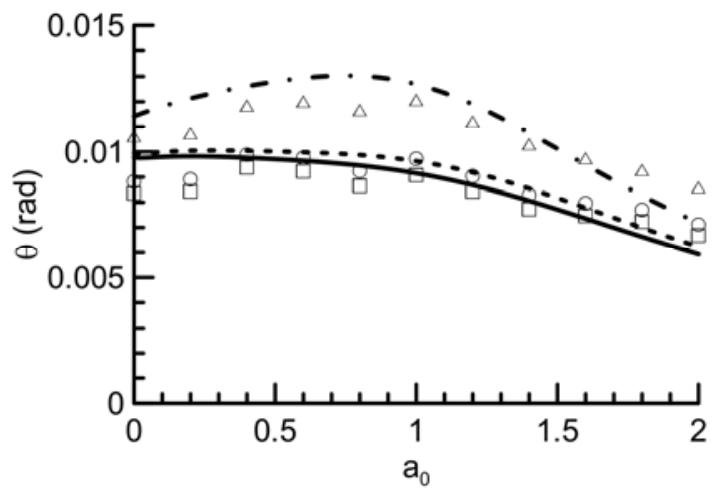

(b) Rotation angles

Fig. 24. Horizontal displacements and rotation angles of the caisson and the CCPFs in the homogenous soil. 

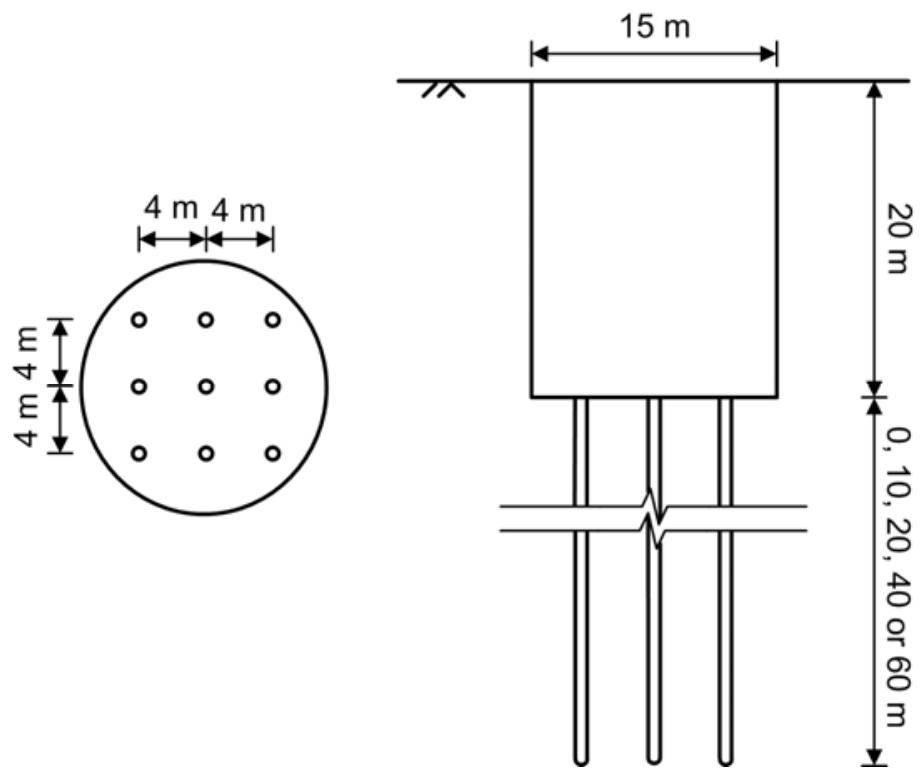

Fig. 25. The layout of the piles beneath the caisson and the geometric attribute of the CCPF from the side view.

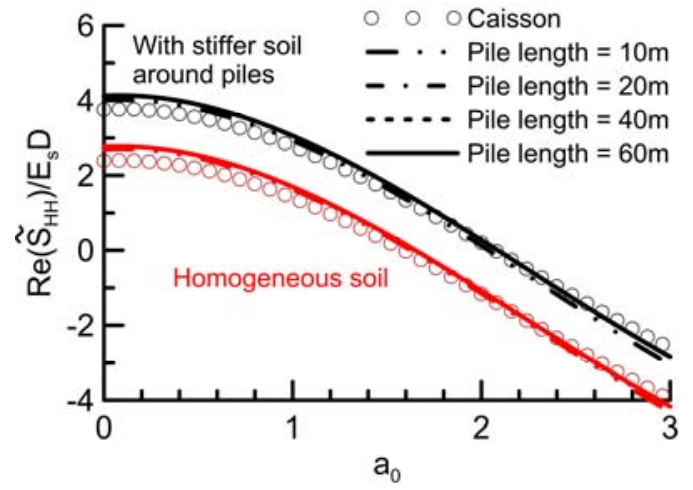

(a) Real part

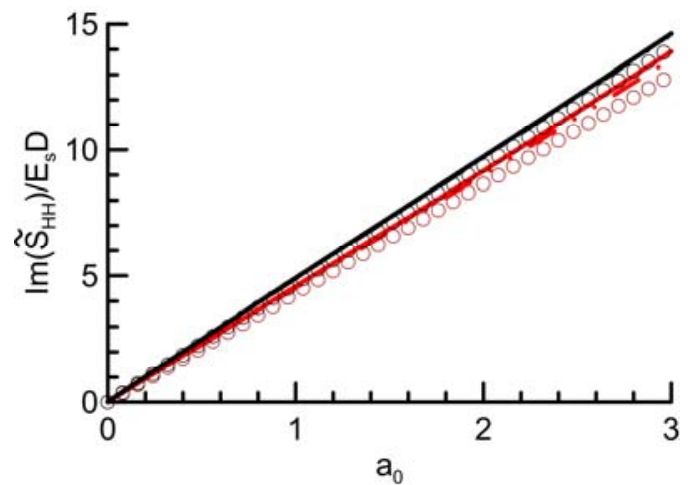

(b) Imaginary part

Fig. 26. Normalized complex swaying stiffness atop the CCPF. 


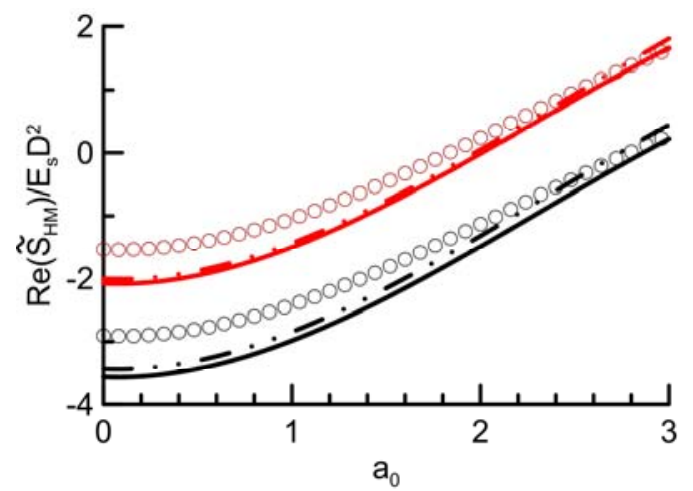

(a) Real part

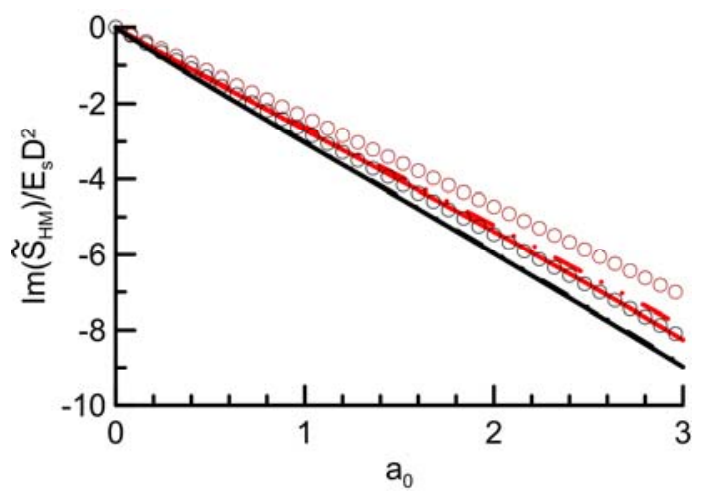

(b) Imaginary part

Fig. 27. Normalized complex cross swaying-rocking stiffness atop the CCPF.

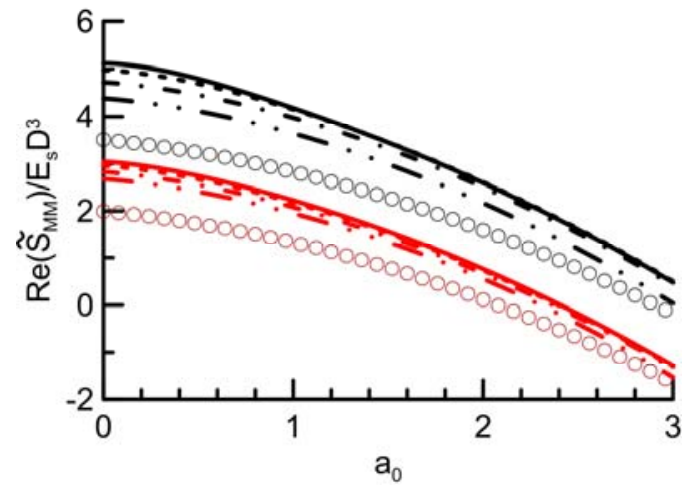

(a) Real part 


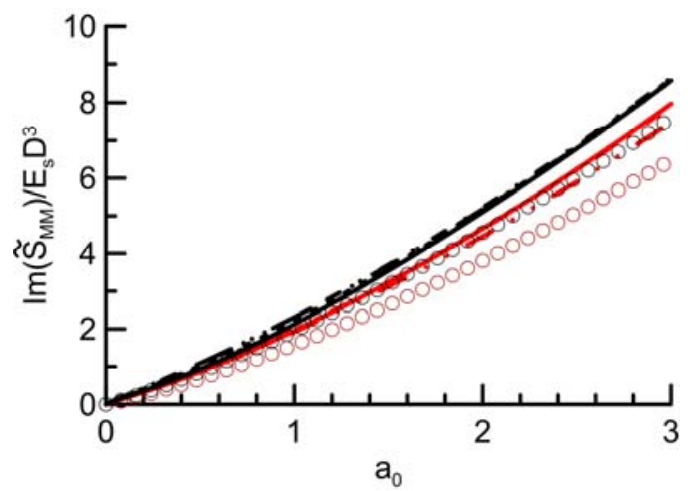

(b) Imaginary part

Fig. 28. Normalized complex rocking stiffness atop the CCPF.

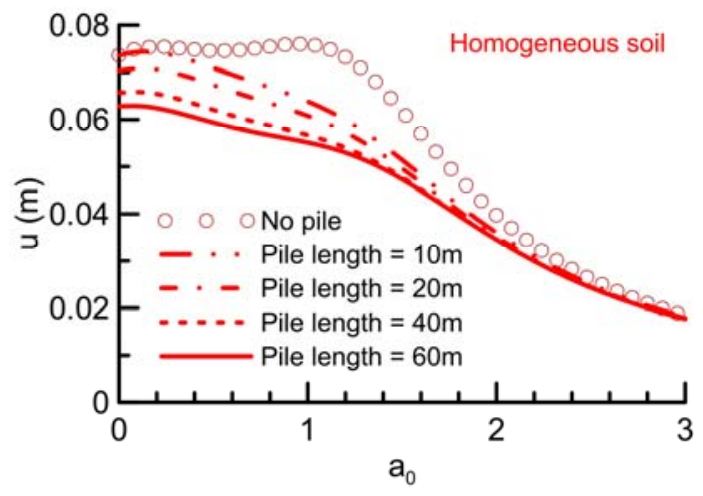

(a) Horizontal displacements

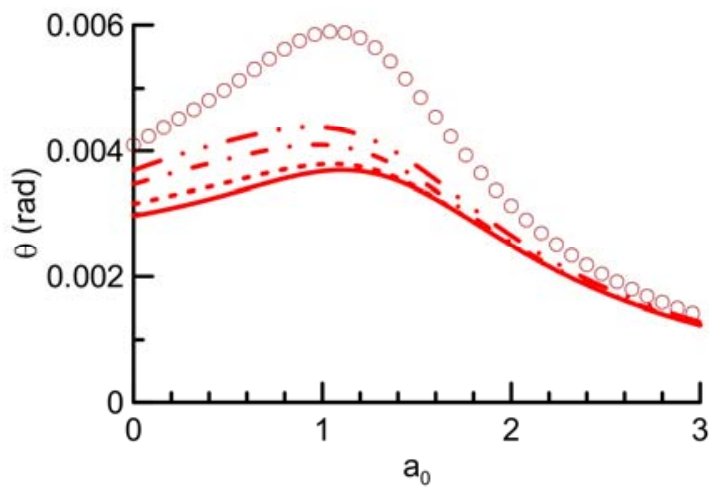

(b) Rotation angles

Fig. 29. Horizontal displacements and rotation angles of the CCPF in homogeneous soil. 


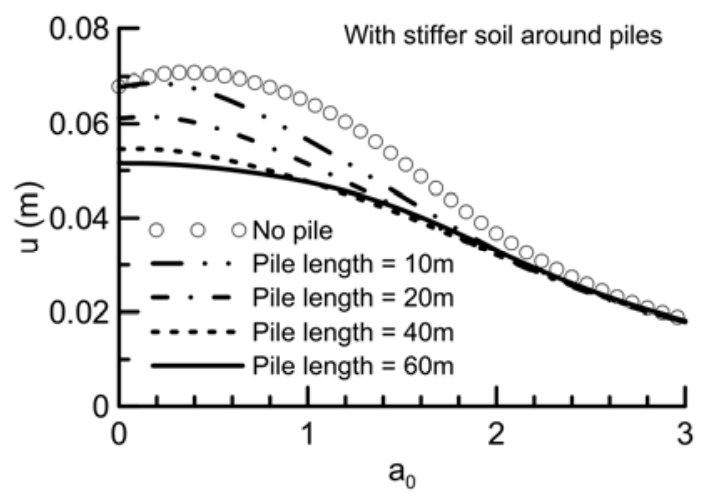

(a) Horizontal displacements

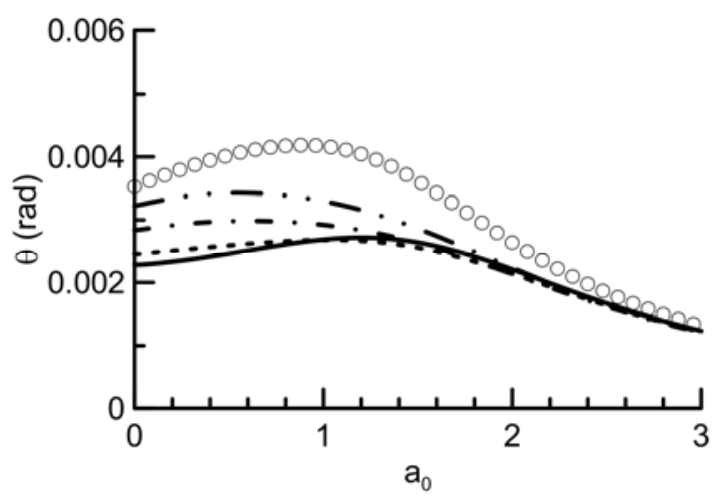

(b) Rotation angles

Fig. 30. Horizontal displacements and rotation angles of the CCPF with stiffer soil around the piles. 